\title{
Radical Cyclization of Trichloroacetamides: Synthesis of Lactams
}

\author{
Guilhem Coussanes \\ Xavier Vila ${ }^{1}$ \\ Faïza Diaba \\ Josep Bonjoch*
}

Laboratory of Organic Chemistry, Faculty of Pharmacy, University of Barcelona, Av. Joan XXIII 27-31, 08028 Barcelona, Spain josep.bonjoch@ub.edu

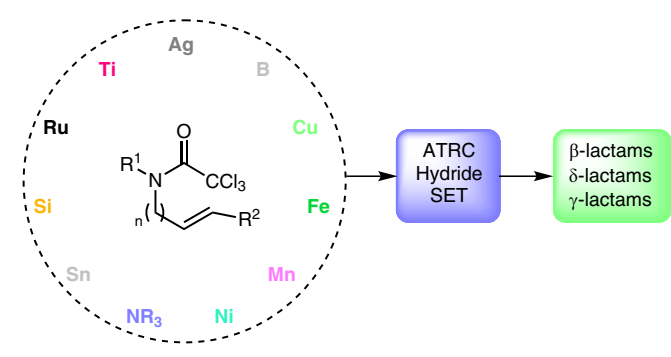

Received: 07.10.2016

Accepted after revision: 01.12.2016

Published online: 03.01.2017

DOI: 10.1055/s-0036-1588383; Art ID: ss-2016-z0711-sr

Abstract Trichloroacetamides can act as radical precursors to synthesize nitrogen-containing heterocycles in a variety of processes, mainly involving atom transfer radical cyclizations (ATRC), mediated by $\mathrm{Cu}(\mathrm{I})$ or $\mathrm{Ru}(\mathrm{II})$ catalysts, and the hydride reductive method, employing either $\mathrm{Bu}_{3} \mathrm{SnH}$ or $\left(\mathrm{Me}_{3} \mathrm{Si}\right)_{3} \mathrm{SiH}$, or recently $\mathrm{NaBH}_{3} \mathrm{CN}$. Additionally, amine-mediated single-electron transfer cyclizations, as well as radical processes promoted by $\mathrm{Ni}, \mathrm{Fe}, \mathrm{Mn}, \mathrm{Ti}$, and Ag, have been developed.

1 Introduction

2 Atom Transfer Radical Cyclizations (ATRC)

2.1 Copper-Mediated Reactions

2.2 Ruthenium(II)-Mediated Reactions

2.3 ATRC Promoted by Other Metals

3 Photocyclization Reactions

4 Reductive Cyclization via Single-Electron Transfer Processes

4.1 Ni/AcOH-Promoted Cyclizations

4.2 Titanocene(III)-Catalyzed Reactions

4.3 Silver Acetate Mediated Reactions

4.4 Amine-Mediated Single-Electron Transfer

5 Cyclization Involving $\mathrm{M}-\mathrm{H}$ Hydrogen Atom Donors ( $\mathrm{M}=\mathrm{Sn}, \mathrm{Si}, \mathrm{B})$

5.1 $\mathrm{Bu}_{3} \mathrm{SnH}$-Mediated Reactions

$5.2\left(\mathrm{Me}_{3} \mathrm{Si}\right)_{3} \mathrm{SiH}$ (TTMSS)-Mediated Reactions

5.3 Borohydride-Mediated Radical Cyclizations

6 Concluding Remarks

Key words radical reactions, lactams, cyclization, nitrogen heterocycles, hydrides, atom transfer, reduction, haloacetamides

\section{Introduction}

Radical cyclization reactions comprise three basic steps: selective radical generation, radical cyclization, and after the formation of one or more carbon-carbon bonds, conversion of the new radical into the final stable product (Figure 1).

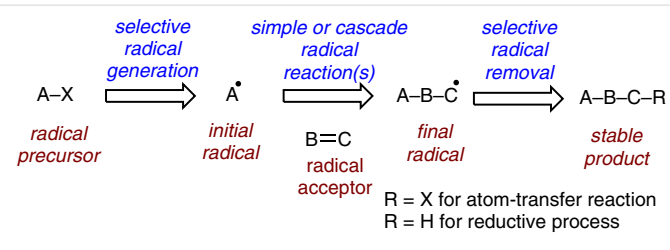

For radical cyclizations of trichloroacetamides: $\mathrm{A}-\mathrm{X}=\mathrm{R}_{2} \mathrm{NCOCl}_{3}$ tethered alkenes $\mathrm{B}=\mathrm{C}$ with electron-withdrawing, -donating or -neutral groups

Figure 1 Radical reactions

Trichloroacetamides have been used since the 1980s for the synthesis of nitrogen-containing heterocycles such as $\gamma-$ lactams, as well as $\beta$ - and $\delta$-lactams, in a variety of radical processes (e.g., atom transfer and hydride transfer). The usefulness of trichloroacetamides as radical precursors relies on the generation of an electrophilic carboradical. Indeed, the two chlorine atoms and carbamoyl moiety act as an electron-withdrawing group, which makes the dichloromethylcarbamoyl radical able to react with any type of alkene as a radical acceptor (Figure 2). In non-reductive conditions, in addition to the formation of the corresponding heterocycle, the process allows the introduction of chlorine atom(s), which can be further functionalized.

This review is focused on the utilization of trichloroacetamides in the synthesis of nitrogen-containing compounds via radical intermediates. The different ring-closing methods have been grouped according to whether the radical process involves a transition-metal-mediated atom

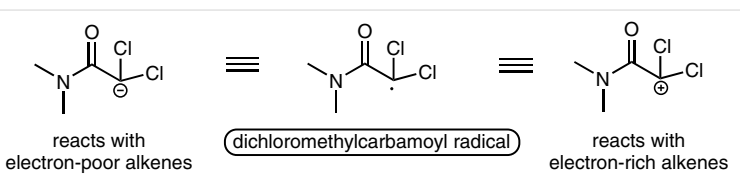

Figure 2 The electrophilic character of the dichloromethylcarbamoyl radical allows an ambiphilic reactivity 


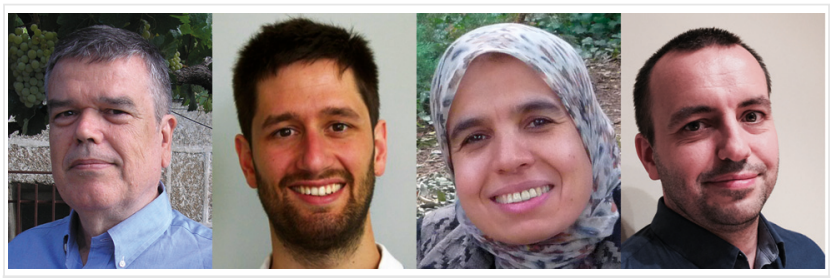

Josep Bonjoch (left) was born in Barcelona (Catalonia, Spain) in 1952. He received his Ph.D. (1979) under the supervision of Professor Joan Bosch at the University of Barcelona, Faculty of Chemistry. He then moved to the Faculty of Pharmacy at the same university, where he became Full Professor of Organic Chemistry in 1992. His main research involves the synthesis of complex nitrogen-containing natural products, and the concomitant development of new synthetic methodology. The main methodological areas in which his group is involved are organocatalysis and radical chemistry. He has described for the first time the total synthesis of twenty natural products, including indole alkaloids (melinonine, echitamidine inter alia), some aeruginosin-type peptides (aeruginosin 298-A), terpenes (nakamurol, xylarenal A, anominine), and phlegmarine alkaloids (cermizine $B$, serratezomine $E$ ). He has published more than 150 papers and supervised 30 Ph.D. theses.

Guilhem Coussanes (second left) was born in Sète, France, in 1989. After receiving his master's degree (2013) in biomolecular chemistry and his engineering degree (2013) in organic chemistry from the National School of Chemistry of Montpellier, he joined the research group of Professor Bonjoch at the Faculty of Pharmacy of the University of Barcelona, where he is completing his Ph.D. working on the total synthesis of calyciphylline A-type alkaloids.

Faïza Diaba (second right) studied chemistry at the University of Constantine, Algeria, and obtained her Ph.D. with Dr. Micheline GrignonDubois at Bordeaux I University, France. She then moved to the University of Barcelona to take up a postdoctoral position with Professor Josep Bonjoch and pursued her scientific career as a Lecturer until 2009 when she was promoted to Associate Professor. Her research interests are focused on developing new synthetic methodologies for the synthesis of nitrogen-containing compounds based on radical processes.

Xavier Vila (right) was born in Hostalric, Spain, in 1976. He graduated in pharmacy in 1999 and received his Ph.D. in 2004 from the University of Barcelona, where he investigated the total synthesis of natural products using radical reactions under the supervision of Professors Josefina Quirante and Josep Bonjoch. After a postdoctoral stay at École Polytechnique (Palaiseau, France) with Professor Samir Z. Zard, working on new radical methodologies using xanthates, he joined the pharmaceutical company Uriach, where he worked as a process chemist, and since 2013 as a project manager.

transfer ${ }^{2}$ or a reductive radical cyclization, ${ }^{3}$ and the reagents required in each case. A section about nickel-promoted cyclizations and single-electron transfer (SET) processes $^{4}$ has also been included. ${ }^{5}$

The trichloroacetamides used as starting materials in these processes are easily synthesized from the corresponding amines by treatment with trichloroacetyl chloride in the presence of triethylamine or pyridine in dichloromethane at $0{ }^{\circ} \mathrm{C} .{ }^{6}$ They can also be obtained by an Overman rearrangement of trichloroacetimidates obtained by condensation between an allylic alcohol and a trichloro-

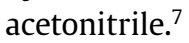

\section{Atom Transfer Radical Cyclizations (ATRC)}

An atom transfer radical reaction, also known as the Kharasch reaction, consists of a metal-catalyzed radical addition of a carbon-halogen bond to an alkene.

\subsection{Copper-Mediated Reactions}

The Stauffer Chemical Company ${ }^{8}$ was the first to report a copper-mediated ATRC of trichloroacetamides, e.g., 1a to afford the potential herbicide $\gamma$-lactam $\mathbf{2 a}$ (Scheme 1). The reaction was carried out in toluene at reflux using $\mathrm{Cu}_{2} \mathrm{O}$ :pyridine.
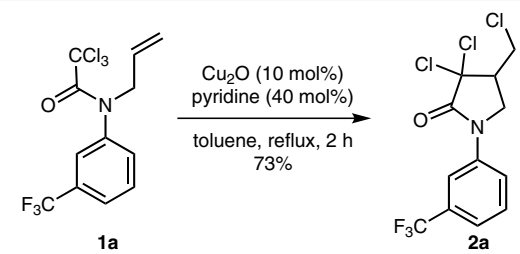

Scheme 1 First example of the radical cyclization of a trichloroacetamide

\subsection{1 $\mathrm{CuCl}$}

The first use of $\mathrm{CuCl}$ to promote a chlorine transfer radical cyclization in the trichloroacetamide field was described in 1984 by Itoh for the synthesis of $\gamma$-lactams 2 by cyclization of $\mathrm{N}$-allyltrichloroacetamides $\mathbf{1}$, as shown in

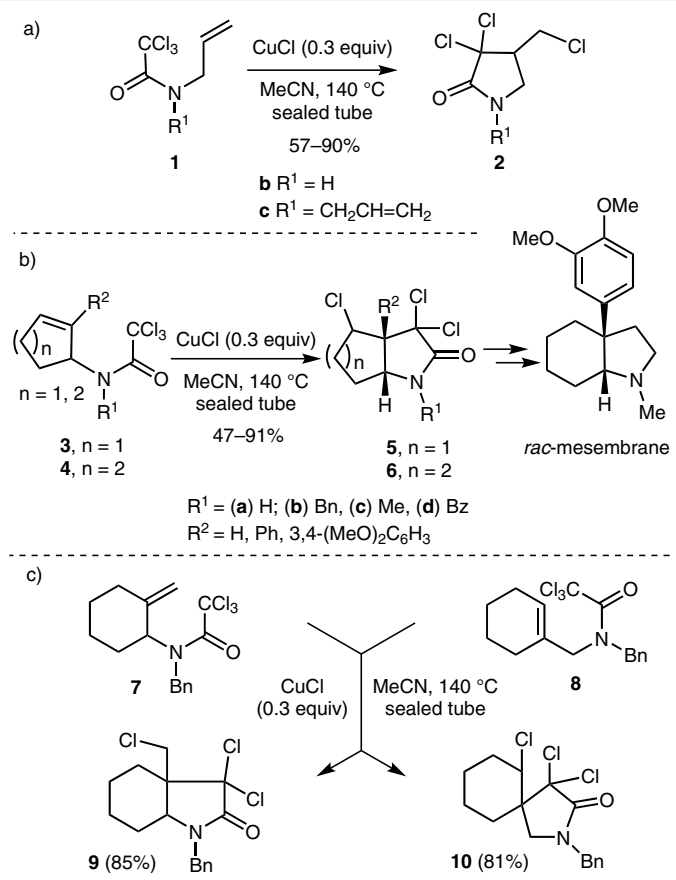

Scheme 2 Synthesis of $\mathrm{Y}$-lactams and bicyclic lactams 
Scheme 2 (a). ${ }^{6}$ The process required a sub-stoichiometric amount of the catalyst and high temperatures (acetonitrile in a sealed tube). This method was extended to the synthesis of bicyclic lactams, starting from trichloroacetamides $\mathbf{3}$ and $\mathbf{4}^{9}$ to afford cis-octahydrocyclopenta[b]pyrroles $\mathbf{5}$ and cis-octahydroindoles $\mathbf{6}$, embedding the bicyclic core of mesembrine alkaloids (Scheme 2, b). Moreover, from trichloroacetamides $\mathbf{7}$ and $\mathbf{8}$, bicyclic lactams $\mathbf{9}$ and $\mathbf{1 0}$ were synthesized (Scheme 2, c).

In 1987, Yamazaki applied the same reaction conditions to $\mathrm{N}$-trichloroacetyltetrahydroisoquinoline 11. Through a 6-exo radical cyclization, benzo[a]quinolizine $\mathbf{1 2}$ (Scheme 3 ), the azatricyclic fragment of emetine alkaloids, was obtained in an excellent yield. ${ }^{10}$

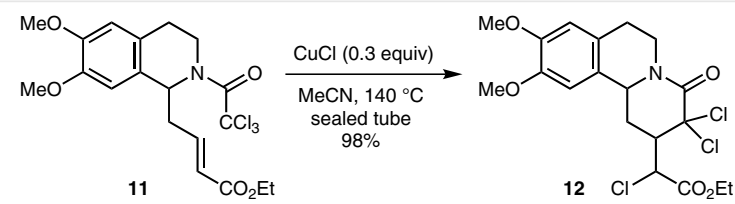

Scheme 3 Synthesis of a benzo[a]quinolizine

The same reaction conditions were employed to synthesize the pyrrolizidine alkaloids, pseudoheliotridane and trachelantamidine, starting from trichloroacetamide 13 derived from L-proline via the indolizidine $\mathbf{1 4}$ (Scheme 4). ${ }^{11}$

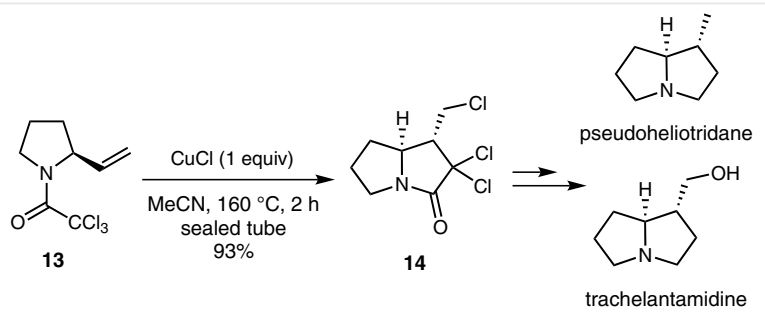

Scheme 4 Synthesis of pyrrolizidine alkaloids

In 2010, Ghelfi optimized the reaction conditions of "ligand-free-like' ATRC $(\mathbf{1 d} \rightarrow \mathbf{2 d})$ by changing the solvent to DMF, which acts as a ligand. This allowed a reduction of the temperature to $60{ }^{\circ} \mathrm{C}$ and the catalyst loading to $10 \mathrm{~mol} \%$ (Scheme 5). ${ }^{12}$ In a similar process, the $N$-methylsulfonyl compound $\mathbf{1 e}$ led to $\mathbf{2 e}$ when using acetonitrile as the solvent, and after warming in DMF elimination of $\mathrm{HCl}$ afforded 15 (Scheme 5). ${ }^{13}$ The process can be run stepwise or sequentially, but the stepwise process was preferred due to cleaner reactions.

\subsection{2 $\mathrm{CuCl}$ and Bidentate Ligands}

Early on, Itoh discovered that $\mathrm{CuCl}$ employed with bidentate amine ligands such as bipyridine (bpy) allowed the radical reactions to take place at lower temperatures

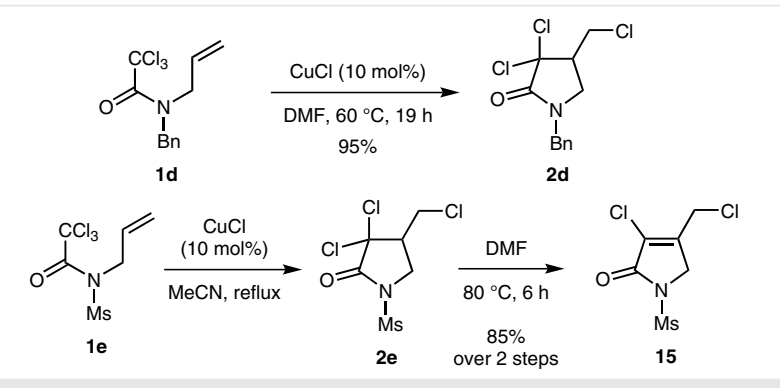

Scheme 5 A sequential ATRC/elimination process

and in a shorter time. ${ }^{14}$ The cyclization does not occur if there is a free $\mathrm{NH}$ group in the substrate, as it reacts with the $\mathrm{Cu}$ catalyst to form an inactive $\mathrm{Cu}$-amide species. As shown in Scheme 6, cis- and trans- $\beta, \gamma$-dialkyl $\gamma$-lactams 17 were stereoselectively prepared from $N$-substituted $N$-allyltrichloroacetamides 16, using CuCl:bpy in dichloromethane. The diastereoselection depended on the $\mathrm{N}$-substituent and the temperature. When $\mathrm{Z}=\mathrm{Bn}$, the trans diastereomer 17a was obtained in a ratio from $95: 5$ at $-15{ }^{\circ} \mathrm{C}$, whereas with an EWG ( $\mathrm{Z}=\mathrm{Ts}, \mathrm{Cbz}, \mathrm{Boc})$ at the nitrogen atom, the cis isomers 17b were obtained in a ratio from 20:80 to 10:90 at $-70{ }^{\circ} \mathrm{C}$ or $-15{ }^{\circ} \mathrm{C}$. The lower the temperature, the more diastereoselective the reaction.
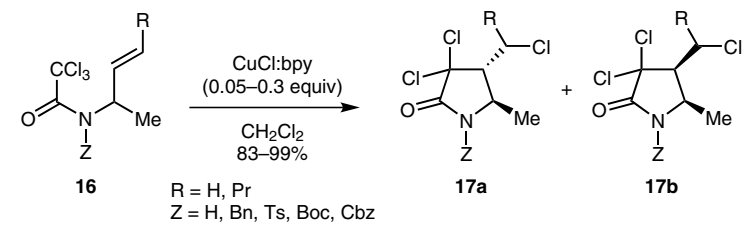

Scheme 6 Low-temperature process in $\mathrm{N}$-substituted amides

The CuCl:bpy system was used to synthesize cis-3a-aryloctahydroindole 19 from trichloroacetamide $18,{ }^{15}$ a useful compound for the synthesis of mesembrane and crinane alkaloids (Scheme 7). Nagashima postulated that the introduction of an EWG at the $\mathrm{N}$-allyltrichloroacetamide facilitates the cyclization by lowering the LUMO of the trichloroacetyl moiety, therefore favoring the abstraction of a $\mathrm{Cl}$ by the $\mathrm{Cu}(\mathrm{I})$ complex via electron transfer. Moreover, for relatively large acyl substituents (e.g., $\mathrm{CCl}_{3}$ ), the barrier for $\mathrm{N}-$ (CO) amide bond rotation is moderate, enabling an easier cyclization process from the advantageous $E$-rotamer. ${ }^{15,16}$

In 1999, Nagashima's group introduced a procedure for the $\alpha$-functionalization of $\alpha, \alpha, \gamma$-trichlorinated $\gamma$-lactams obtained by a CuCl:bpy-mediated cyclization of $N$-allyltrichloroacetamides. ${ }^{17}$ The reaction can be stepwise, the formation of the $\gamma$-lactam followed by the reaction with an olefin, or sequential, as the $\gamma$-lactam bearing two chlorine atoms at the $\alpha$-position of the carbonyl group is less reactive than the trichlorinated starting material. As depicted in Scheme 8 , the reaction of $\alpha, \alpha, \gamma$-trichlorinated $\gamma$-lactams 2d,f with allyltrimethylsilane provided $\mathbf{2 0}$, which after 


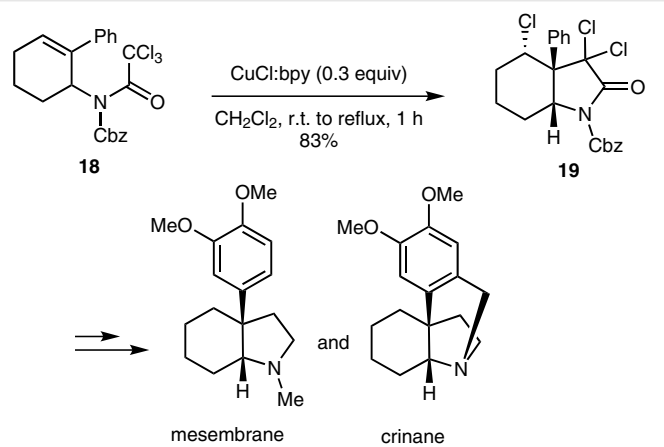

Scheme 7 Synthesis of cis-3a-aryloctahydroindoles

treatment with silica gel gave $\alpha$-alkylated $\gamma$-lactam 21 as an epimeric mixture. $N$-Benzyl compounds needed a higher amount of catalyst to afford comparable yields, as they are less reactive than $\mathrm{N}$-tosyl compounds (vide supra). In a onepot procedure, trichloroacetamide $\mathbf{1 f}$ was treated with allyltrimethylsilane and heated in dichloroethane, giving allylated lactam 21 in 80\% yield (Scheme 8).
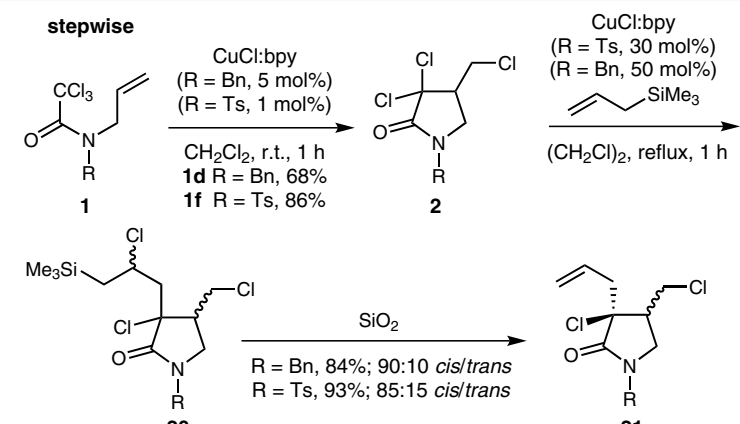

$$
\text { sequential }
$$

$1 f$

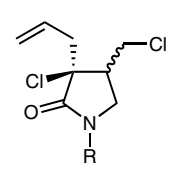

21
Scheme 8 ATRC-intermolecular/allylation reactions

It is noteworthy that a domino process ${ }^{18}$ was also developed, involving two sequential intramolecular ATRCs starting from trichloroacetamide $\mathbf{2 2}$ to afford $\mathbf{2 3}$ in good yield, in<smiles>CC(C)=CCCC(C)=CCNC(=O)Cl</smiles>

22

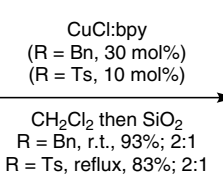
$\begin{aligned} R & =\mathrm{Bn}, \text { r.t., } 93 \% ; 2: 1 \\ R & =\mathrm{Ts} \text {, reflux } 83 \% ; 2: 1\end{aligned}$ Re

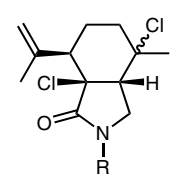

23
Scheme 9 One-pot biscyclization which a second intramolecular alkylation took place from an $\alpha, \alpha$-dichlorolactam (Scheme 9). ${ }^{17}$ Thus, a catalytic $\mathrm{Cu}(\mathrm{I})$ radical-triggered biscyclization was accomplished.

Using the catalytic system CuCl:bpy in toluene at reflux, Parsons and co-workers developed an efficient synthesis of unsaturated pyrrolidinones by 5 -endo cyclization of $\mathrm{N}$-cyclohexenyltrichloroacetamide $\mathbf{4 b}$. The first step consists of an ATRC, followed by a thermal elimination of $\mathrm{HCl}$ to afford 24a (Scheme 10). ${ }^{19}$

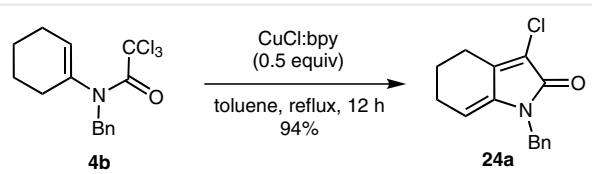

Scheme 10 Synthesis of unsaturated bicyclic pyrrolidinones

In addition, $\beta$ - or $\gamma$-lactams were obtained from trichloroenamides, depending on whether a 4-exo or 5-endo cyclization took place (Scheme 11). ${ }^{20}$ Besides the structure of the compound, the solvent used played a significant role in the selectivity of the reaction. In the depicted example, when the reaction was carried out in toluene from 25 , the major product was produced by a 5-endo cyclization, whereas if it was performed in acetonitrile, $\beta$-lactam 26a was obtained exclusively. This is because $\mathrm{CuCl}$ is soluble in acetonitrile, and the kinetic 4-exo cyclization is followed by a rapid oxidation of the resulting tertiary radical to afford the $\beta$-lactam product (i.e., 26a). On the contrary, the catalyst is less soluble in toluene, and as a consequence the rate of oxidation is expected to be slower. This allows equilibration to the more stable radical (5-endo thermodynamic product) to take place prior to oxidation, thus leading to a predominance of $\gamma$-lactam 27. Treatment of this unstable $\gamma$ lactam with methanol and silica afforded the $\gamma$-lactams $\mathbf{2 8}$.

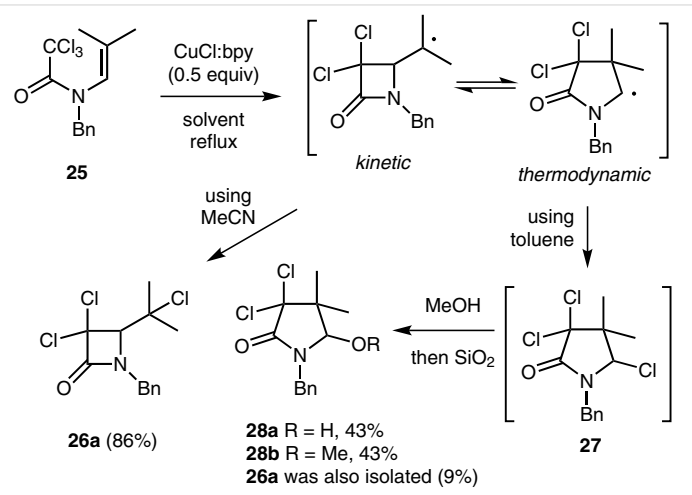

Scheme 11 Influence of the solvent on trichloroenamide cyclizations

This methodology was extended to the synthesis of the anti-epileptic drug gabapentin marketed by Pfizer, ${ }^{21}$ in which the key step is a CuCl:bpy-mediated 5-endo cyclization of trichloroenamide $\mathbf{2 9}$ leading to $\mathbf{3 0 a}$, as depicted in 
Scheme 12. Removal of the three chlorine atoms led to the hydroxy-pyrrolidinone $\mathbf{3 0 b}$, which arose from the hydrolysis of the intermediate acyl iminium. Unlike the previous results (Scheme 11), the 5-endo pathway is preferred to the 4-exo due to the bulkiness generated by the cyclohexane ring.

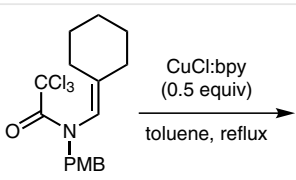

29

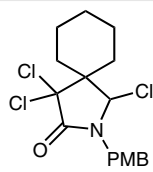

$30 \mathrm{a}$

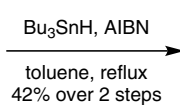

$42 \%$ over 2 steps<smiles>CCC(C)C</smiles>

Scheme 12 Synthesis of gabapentin

Ghelfi and Parsons decided to introduce TMEDA, a cheaper ligand than bipyridine but just as efficient. ${ }^{22}$ Starting from $N$-allyltrichloroacetamides $\mathbf{1 d}$ and 16, and using only $10 \mathrm{~mol} \%$ of CuCl:TMEDA in acetonitrile, $\gamma$-lactams $\mathbf{2 d}$ and $\mathbf{1 7}$ were afforded, respectively, in excellent yields (Scheme 13).

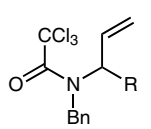

1d $\mathrm{R}=\mathrm{H}$ $16 \mathrm{R}=\mathrm{Me}$
$\mathrm{N}$
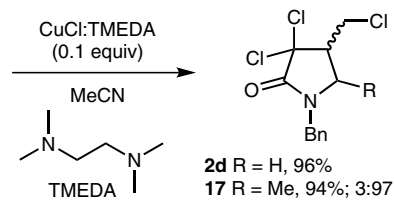

$17 \mathrm{R}=\mathrm{Me}, 94 \% ; 3: 97 \mathrm{cis} /$ trans
Scheme 13 Synthesis of $\mathrm{Y}$-lactams using the CuCl:TMEDA system

Subsequently, a CuCl:TMEDA-mediated cyclization of $\mathrm{N}$ dimethylamino- $N$-allyltrichloroacetamides was developed to afford $\mathrm{N}$-dimethylaminopyrrolidones $(\mathbf{1 g} \rightarrow \mathbf{2 g}$ ) (Scheme 14). ${ }^{23}$ The dimethylamino group was introduced because it was easier to remove from the cyclic compounds compared to a benzyl moiety. It was also envisaged that it would form a complex with the $\mathrm{CuCl}$, which could lead to cyclization in the absence of TMEDA. However, without TMEDA, only the starting material was recovered, which emphasized that a bidentate rather than a monodentate amine ligand was required.<smiles>C=CCN(C(=O)C(Cl)(Cl)Cl)N(C)C</smiles>

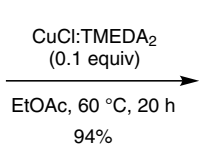

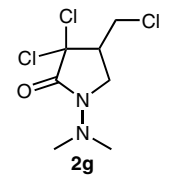

2g
Scheme 14 ATRC of trichloroacetylhydrazines
Another application of this ligand for $\mathrm{Cu}(\mathrm{I})$ was the ATRC of $N$ - $\alpha$-perchloroacyl-ketene- $N, S$-acetal 31, which after oxidation afforded the disubstituted maleic anhydride 32 (Scheme 15). ${ }^{24}$

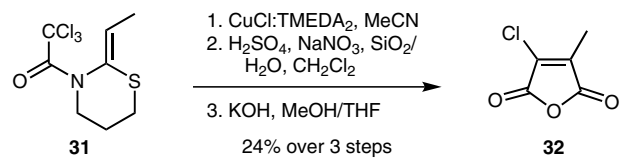

Scheme 15 Synthesis of disubstituted maleic anhydrides

Stevens et al. used the CuCl:TMEDA methodology for the synthesis of spiroindoles (Scheme 16), ${ }^{25 a}$ consisting of an intramolecular 5-exo radical cyclization of the tether indole trichloroacetamide 33a to 34 . No product of a 6-endo cyclization was detected. As an extension, a domino 5-exoand 6-endo-trig cyclization from 33b was developed to access diazatetracyclic compound $\mathbf{3 5}$, obtained in moderate yield. $^{25 b}$
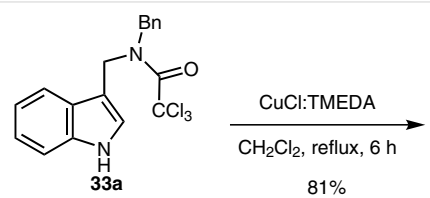<smiles>CN1CC2(CN(Cc3ccccc3)C(=O)C2(Cl)Cl)c2ccccc21</smiles><smiles>C=CCCn1cc(CN(Cc2ccccc2)C(=O)C(Cl)(Cl)Cl)c2ccccc21</smiles>

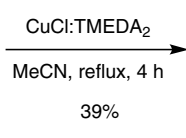<smiles>CCC1N2CCC(Cl)CC2C12CN(Cc1ccccc1)C(=O)C2(Cl)Cl</smiles>

Scheme 16 Synthesis of spiroindoles

Clark worked on the development of supported multidentate imine ligands such as A, derived from $\mathrm{N}$-alkyl-2pyridylmethanimines (Scheme 17), ${ }^{26}$ which complexed $\mathrm{Cu}(\mathrm{I})$. These ligands were found to be effective in catalyzing the radical cyclization of $\mathrm{N}$-allyltrichloroacetamides to furnish pyrrolidinones. The polymeric support was shown to have very little effect on the reaction, whereas the nature of the ligand was crucial. These catalysts can be reused several times, albeit with a drop in activity due to copper leaching.
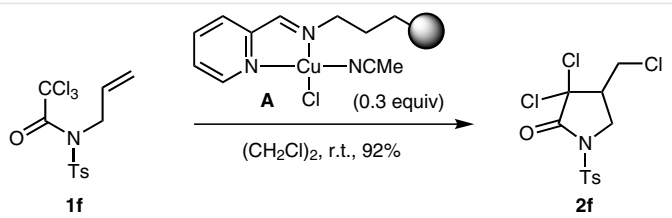

Scheme 17 ATRC with a solid-supported amine ligand

A similar ligand $\mathbf{B}$ was used in homogeneous conditions to synthesize unsaturated pyrrolidinones and bicyclic pyr- 
rolidinones by a 5-endo radical cyclization of trichloroenamides (4b $\rightarrow$ 24a) (Scheme 18). ${ }^{27}$

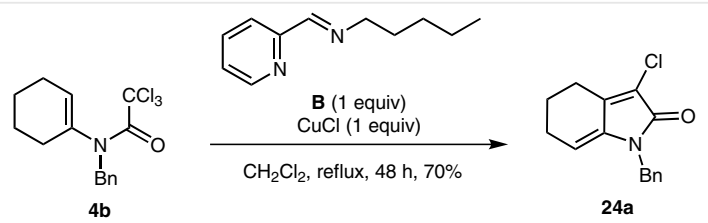

Scheme 18 Synthesis of unsaturated bicyclic pyrrolidinones

The electronic and steric environment of ligand $\mathbf{C}$ was modified to assess the effects on the 5-exo radical cyclization of trichloroacetamide $\mathbf{1 f}$ (Scheme 19). ${ }^{28}$ Substitution at C-6 led to a drop in ligand activity due to steric hindrance, but this was overcome by the electronic effect of a substituent at C-5. The experiment showed that activity was reduced by an inductively withdrawing group such as a methoxy group and slightly improved by an inductively donating group such as methyl.

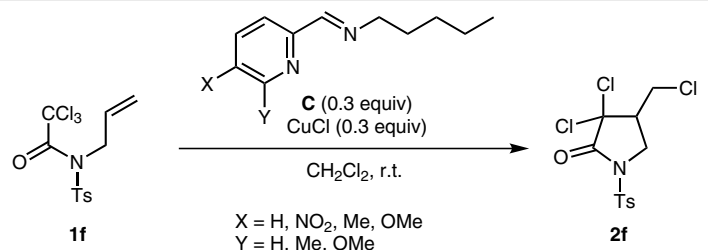

Scheme 19 Ligand optimization for homogeneous catalysis

Nagashima developed a Cu:bpy system encapsulated in polysiloxane gel. ${ }^{29}$ This system showed faster reactivity and a higher total turnover number compared to the non-encapsulated system for 4-exo and 5 exo-trig cyclizations $\{[\mathrm{Cu}:$ bpy $] @ S i$ (0.45 mol\%); TON = 220 vs CuCl:bpy ( $1 \mathrm{~mol} \%)$; TON = 66 $\}$ (Scheme 20).

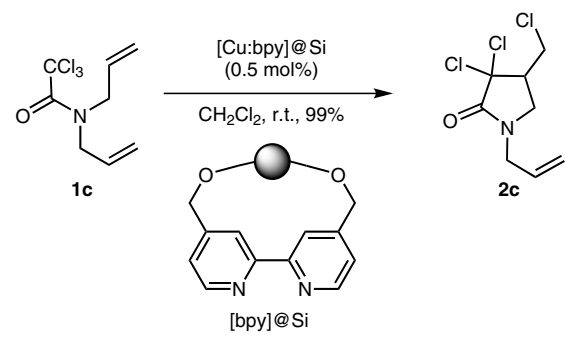

Scheme 20 ATRC with Cu/bpy encapsulated in polysiloxane gel

\subsubsection{CuCl and Multidentate Ligands}

Additionally, multidentate amine ligands such as PMDETA and TPMA were used by Clark et al., and shown to be efficient in the synthesis of $\gamma$ - and $\delta$-lactams. Arising from $N$ tert-butylamide $\mathbf{3 6}$, compound $\mathbf{3 7}$ is one of the few examples of a 2-piperidone obtained by ATRC (Scheme 21). ${ }^{30}$

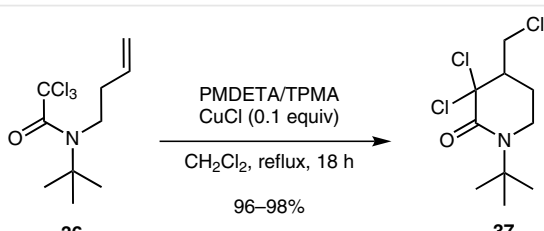<smiles>c1ccc(CN(Cc2ccccn2)Cc2ccccn2)nc1</smiles>

PMDETA

Scheme 21 Synthesis of $\delta$-lactams using multidentate amine ligands

When using the CuCl:TPMA system for the radical cyclization of 1-substituted enamides, the substituent was able to stabilize the cyclized radical to force the 5-endo process. ${ }^{31}$ Thus, from enamide $\mathbf{3 8 a}$, the hydroxylated products 39 were isolated, which probably arose from an oxidation of a radical intermediate by $\mathrm{CuCl}_{2}$ :TPMA, giving an acyl iminium that reacted with water upon work-up. The related compound 38b followed a different pathway, providing the indigoid derivative $\mathbf{4 0}$ of unknown configuration in low yield (Scheme 22). In both cases, a high catalyst loading was
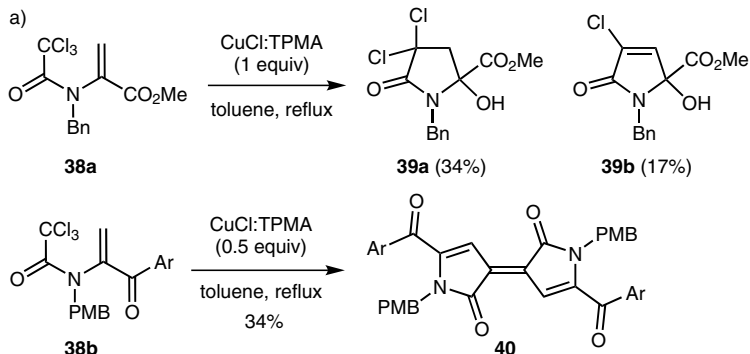

b)
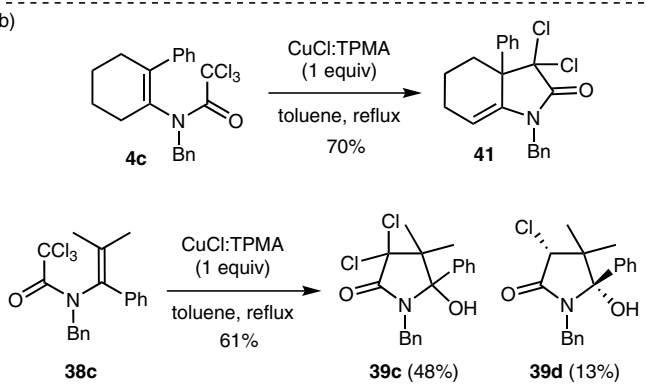

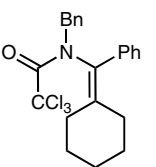

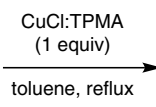

$39 \%$

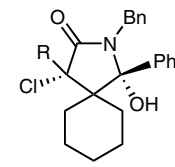

43a $\mathrm{R}=\mathrm{Cl}(23 \%)$ 43b $\mathrm{R}=\mathrm{H} \quad(16 \%)$

Scheme 22 Enamides to y-lactams via a 5-endo radical-polar crossover process 
necessary, and only moderate yields were achieved, as the generation of $\mathrm{HCl}$ deactivated the catalyst system.

Recently, in an extensive study of the substituent effects and rotation barriers ( $\mathrm{N}$-alkenyl and $\mathrm{NCO}$ bonds) in enamide cyclization, ${ }^{16 c} 5$-endo radical-polar crossover reactions from highly substituted enamides (e.g., 4c, 38c, and 42) using $\mathrm{CuCl}$ :TPMA (1 equiv) were reported, leading to the isolation of polyfunctionalized lactams such as $\mathbf{4 1}$ and $\mathbf{4 3}$ (Scheme 22, b).

The regiochemistry of the dienamides was studied under ATRC conditions using CuCl:TPMA. ${ }^{32}$ For 3 -substituted dienamide 44a, the 4-exo cyclization prevailed to afford $\beta$ lactam 45a in a moderate yield. For 2-substituted dienamide 46, the 5-exo cyclization took preference over the 6endo pathway to afford compound $\mathbf{4 7}$ in good yield (Scheme 23). From trienamide $\mathbf{4 4 b}$, using the catalytic system CuCl:TPMA, only the 4-exo cyclization compound $45 \mathrm{~b}$ was isolated in poor yield. ${ }^{31}$<smiles>C=C/C=C/N(CC)C(=O)C(Cl)(Cl)Cl</smiles>

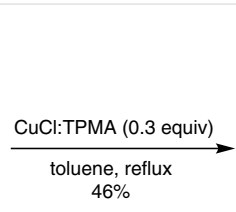<smiles>C=C(/C=C/Pc1ccccc1)N([18OH])C(=O)C(Cl)(Cl)Cl</smiles>

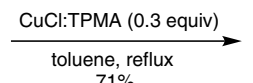

$71 \%$$$
46
$$
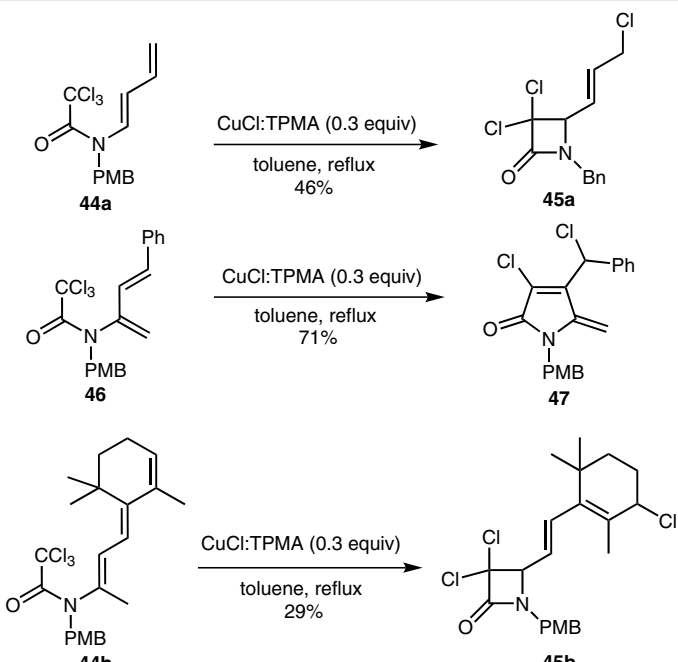

$44 b$

Scheme 23 Regiochemistry study of dienamides and trienamides

Recently, a different type of trichloroacetylhydrazine, i.e., 48, was introduced to achieve tetrahydropyridazinones (e.g., 49) through an ATRC (Scheme 24). The less favored 7endo cyclization gave minor amounts of a diazepanone when the starting alkene was monosubstituted..$^{33}$
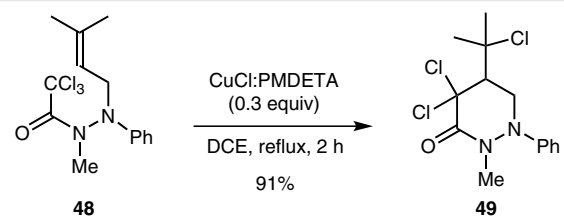

49

Scheme 24 ATRC of trichloroacetylhydrazines

\subsubsection{NHC Ligands}

The use of CuCl:NHC complexes to perform ATRC was introduced by Quayle. ${ }^{34}$ At reflux in dichloroethane, only a slow conversion of $\mathbf{1 d}, \mathbf{f}$ into $\boldsymbol{\gamma}$-lactams $\mathbf{2 d , f}$ was observed, but the yields were drastically improved when using microwave irradiation at $110^{\circ} \mathrm{C}$ (Scheme 25 ).

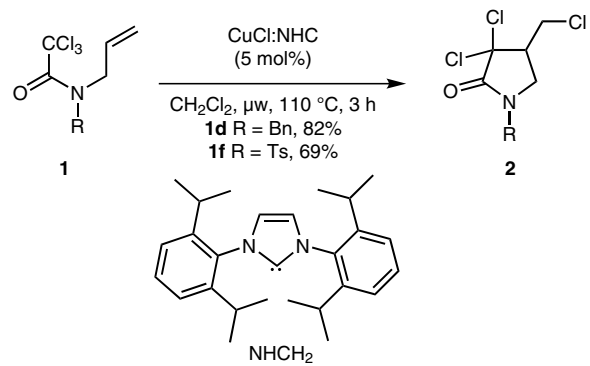

Scheme 25 ATRC using NHC ligands

\subsubsection{Radical Addition to the Aromatic Ring}

When a secondary $\mathrm{N}$-arylsulfonyltrichloroacetamide (e.g., 50) without an alkene as the radical acceptor was treated with a stoichiometric amount of CuCl:PMDETA or $\mathrm{CuCl}$ :trien- $\mathrm{Me}_{6}$, a 5-exo-ipso-cyclization followed with loss of $\mathrm{SO}_{2}$ was observed. The formation of the resulting $\mathrm{N}$-alkyldichlorophenylacetamide 51 (Scheme 26) ) $^{30,35}$ involved a 1,4-aryl migration through a Smiles-type rearrangement.

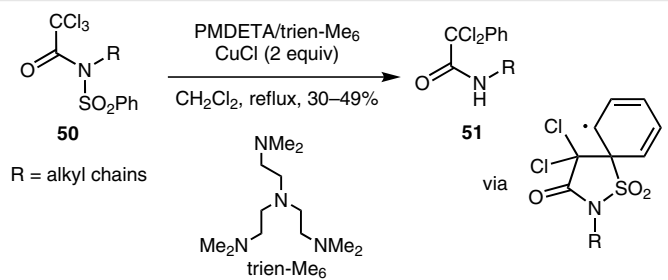

Scheme 26 Aryl migration under ATRC conditions

Treatment of $\mathrm{N}$-benzyltrichloracetamides $\mathbf{5 2}$ with $\mathrm{Cu}(\mathrm{I})$ in 'free-ligand' reaction conditions under microwave irradiation in acetonitrile at $80^{\circ} \mathrm{C}$ led to the spirocyclohexadiene 53a with a labile allylic chlorine atom. The latter was replaced with a hydroxy or other groups by quenching with water, methanol or allylamine, leading to 53b-d (Scheme $27){ }^{36}$ The yields were higher when the bulkiness of the $R$ group was increased.

\subsubsection{Improvements in Copper-Mediated ATRC}

In recent years, several improvements have increased the efficiency of atom transfer radical polymerization processes. ${ }^{37}$ In ATRC of trichloroacetamides catalyzed by $\mathrm{Cu}(\mathrm{I})$, reducing agents have been applied to lower the catalyst 


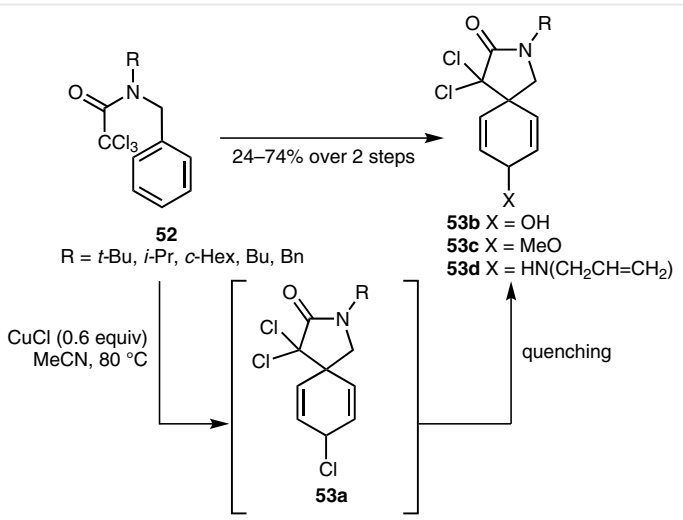

Scheme 27 Dearomatization process under ATRC conditions

load. ${ }^{38}$ Thus, cyclization of $\mathbf{1 d}, \mathbf{f}$ using a system combining ethanol, ascorbic acid (AA) and $\mathrm{Na}_{2} \mathrm{CO}_{3}$ with $\mathrm{CuCl}$ :PMDETA allows the catalyst amount to be reduced to $0.5 \mathrm{~mol} \%$, affording $\gamma$-lactams $\mathbf{2 d , f}$ in excellent yields (Scheme 28). ${ }^{39}$ This constitutes an example of ATRC in which the activator is regenerated by electron transfer (ARGET protocol).
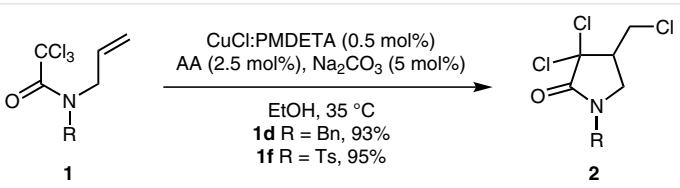

Scheme 28 ARGET-ATRC: Ascorbic acid is used as a reductant

Another protocol involves the use of AIBN as an 'Initiator for Continuous Activator Regeneration' (ICAR-ATRC process). Starting from electron-deficient, -neutral, and -rich alkenes 54, a series of functionalized morphan systems $\mathbf{5 5}$ was generated using CuCl:TPMA (10 mol\%) in dichloroethane (Scheme 29). ${ }^{40}$ Using a $2 \mathrm{~mol} \%$ catalyst loading of $\mathrm{Tp}^{t-\mathrm{Bu}} \mathrm{Cu}(\mathrm{NCMe})$ and $\mathrm{AIBN}(10 \mathrm{~mol} \%)$ as a reducing agent, the cyclization of $\mathbf{5 4}$ with the cyano group embedded took place in high yield.

This methodology has been applied in the synthesis of the $\mathrm{ABC}$ fragment of calyciphylline A type alkaloids. Thus, enol acetate $\mathbf{5 6}$ underwent ATRC in high yield to give a mixture of the dichloro and monochloro derivatives 57a and 57b, which after hydrogenation afforded morphan 57c en route to the targeted azatricyclic core of the calyciphylline $\mathrm{A}$ alkaloid. ${ }^{40 \mathrm{~b}}$

Recently, Ghelfi and Clark developed a 'Supplementary Activator and Reducing Agent' (SARA-ATRC) process using $\mathrm{Cu}(0)$ (wire), the ligand TPMA, and $\mathrm{Na}_{2} \mathrm{CO}_{3}{ }^{38}$ They were able to lower the ligand loading to $0.5 \mathrm{~mol} \%$ to afford $\gamma$-lactam $\mathbf{2 h}$ from $\mathbf{1 h}$ in good yield (Scheme 30 ). The role played by $\mathrm{Na}_{2} \mathrm{CO}_{3}$ in the ligand reduction is still not understood.
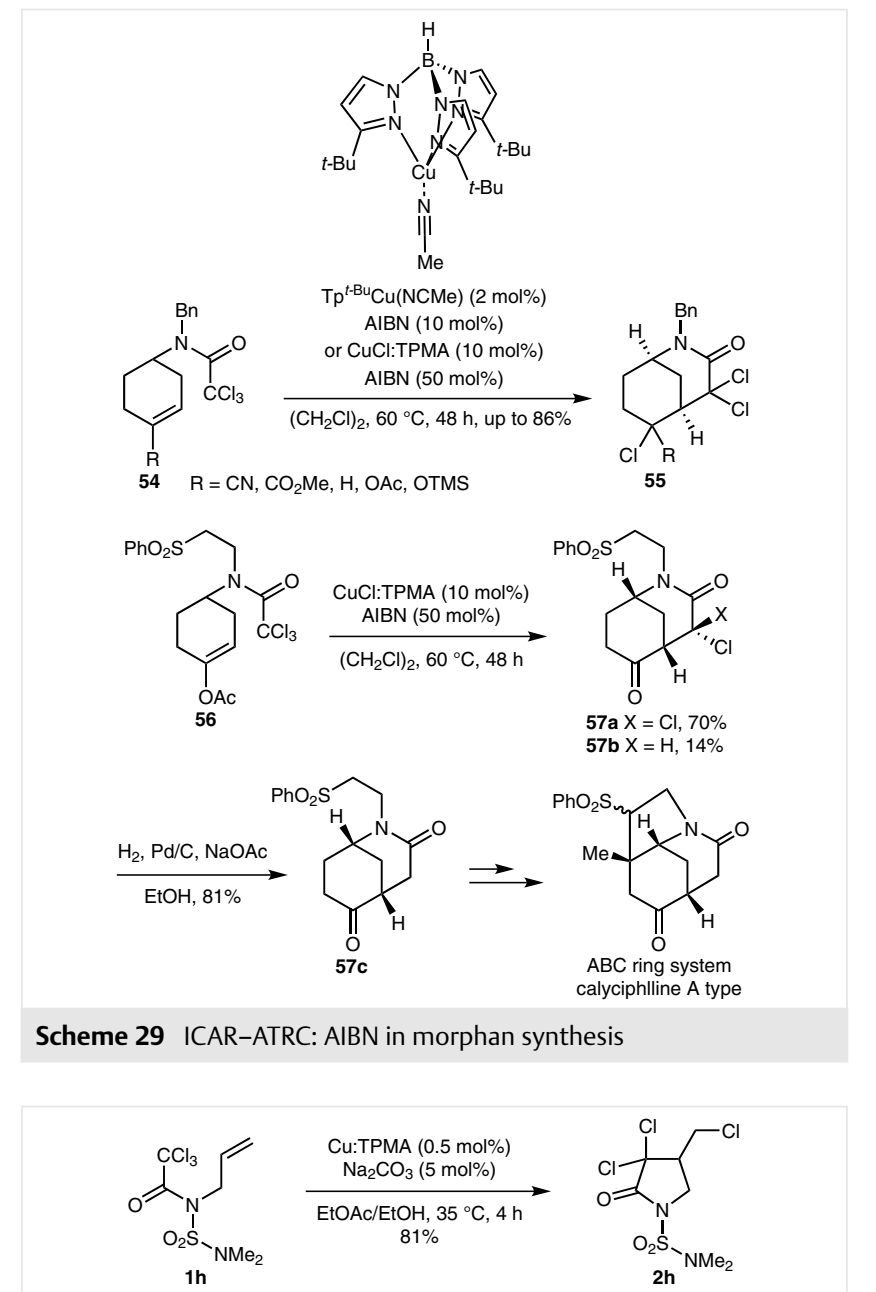

Scheme 30 SARA-ATRC: $\mathrm{Cu}(0)$ as the copper source

\subsection{Ruthenium(II)-Mediated Reactions}

\subsection{1 $\operatorname{RuCl}_{2}\left(\mathrm{PPh}_{3}\right)_{3}$}

Itoh and, later on, Slough, reported the first examples of ATRC upon trichloroacetamides mediated by $\mathrm{RuCl}_{2}\left(\mathrm{PPh}_{3}\right)_{3}$. Several pyrrolidinones $\mathbf{1 7}$, spirocyclic $\gamma$-lactams and hexahydroindoles $\mathbf{5}$ and $\mathbf{6}$ were obtained in good yields in spite of the harsh conditions used (benzene or xylenes at $140{ }^{\circ} \mathrm{C}$ in a sealed tube), starting from $\mathrm{N}$-allyltrichloroacetamides 16 and the related cyclic trichloroacetamides $\mathbf{3}$ and $\mathbf{4}$ (Scheme 31). 6,9,14,41,42

In parallel to his work with $\mathrm{CuCl}$, Parsons developed a $\mathrm{RuCl}_{2}\left(\mathrm{PPh}_{3}\right)_{3}$-mediated ATRC toward the synthesis of $\beta$ - or $\gamma$-lactams starting from $\mathrm{N}$-vinylic trichloroacetamides $(25$ or 58). As depicted in Scheme 11, the use of CuCl:bpy in toluene led preferentially to the 5-endo cyclization product (kinetic product) thanks to the lower solubility of $\mathrm{CuCl}$ in this solvent. On the other hand, the use of $\mathrm{RuCl}_{2}\left(\mathrm{PPh}_{3}\right)_{3}$ in toluene afforded the 4-exo cyclization product (Scheme 32) 
<smiles>[2H]C(Cl)C1C([2H])N([3H])C(=O)C1(Cl)Cl</smiles>

$\mathrm{R}^{1}=\mathrm{Me}, \mathrm{Ph}, \mathrm{Pr}, \mathrm{CO}_{2} \mathrm{Me}, \mathrm{CH}_{2} \mathrm{OAC}$

$\mathrm{R}^{2}=\mathrm{H}, \mathrm{Me}, \mathrm{Pr}$

$\mathrm{Z}=\mathrm{H}, \mathrm{Bn}, \mathrm{Ts}, \mathrm{Boc}, \mathrm{Cbz}$

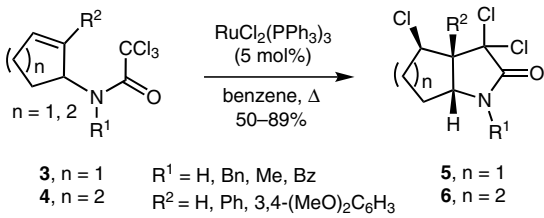

Scheme $31 \mathrm{Ru}(\mathrm{II})$-mediated synthesis of $\mathrm{y}$-lactams

due to its higher solubility, causing the intermediate $\beta$-lactam radical to rapidly oxidize. ${ }^{20}$ Starting from the more sterically hindered amide $\mathbf{5 8}$, the 5-endo pathway was favored, and pyrrolones $\mathbf{5 9}$ embedding the structure of the alkaloid pulchellalactam were obtained. ${ }^{21}$<smiles>CC(C)=CN(Cc1ccccc1)C(=O)C(C)(C)C(=O)OC(C)(C)C</smiles>
25<smiles>C/C=C(\CC)N(Cc1ccccc1)C(=O)C(Cl)(Cl)Br</smiles>
58

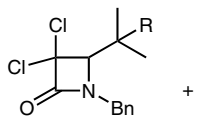

$26 \mathrm{R}=\mathrm{Cl}, 45 \%$<smiles>CC1=C(Cl)C(=O)N(Br)C1=CCC1CC1C</smiles><smiles>CC1=CC(=O)N/C1=C\C(C)C</smiles>

pulchellalactam
Scheme $32 \mathrm{Ru}(\mathrm{II})$-mediated cyclization of trichloroenamides

Sutherland, starting from the enantiopure MOM-ether 60, developed a synthetic sequence involving an Overman rearrangement to achieve trichloroacetamide 61. Ringclosing metathesis (RCM) of the latter gave $\mathbf{6 2}$, and an ATRC, employing $\mathrm{RuCl}_{2}\left(\mathrm{PPh}_{3}\right)_{3}$, achieved enantiopure bicyclic $\gamma$ lactam 63 in good yield (Scheme 33) ${ }^{43}$

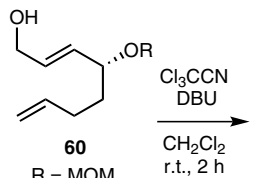<smiles>C=CCC[C@@H](/C=C/COC(=N)C(Cl)(Cl)Cl)Pc1ccccc1</smiles><smiles>C=CCC[C@@H](O)C(C=C)NC(=O)C(F)(Cl)Cl</smiles>

61

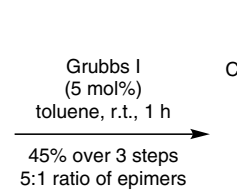

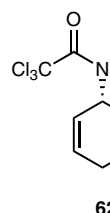

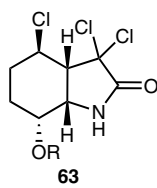

63
Scheme $33 \mathrm{Ru}(\mathrm{II})$-mediated synthesis of an enantiopure $\mathrm{y}$-lactam
Recently, Shi also employed these conditions as the key step in building the morphan ring system $(\mathbf{6 4} \rightarrow \mathbf{6 5})$ of aspidophylline A (Scheme 34). ${ }^{44}$ Notably, both applications constitute scarce examples of the cyclization of monosubstituted trichloroacetamides ( $\mathrm{NH}$ in the structure), whose Z-rotamer at room temperature is unsuitable for cyclization.

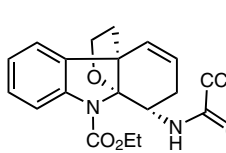

64

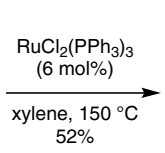<smiles>C/C=C1/CN(C=O)[C@H]2C[C@@H]1[C@@H](C(C)=O)[C@]1(C)c3ccccc3NC21OC</smiles>

aspidophylline $A$

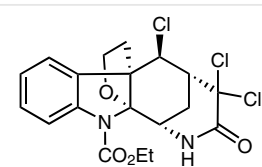

65
Scheme 34 Synthesis of aspidophylline A

\subsubsection{Other Ruthenium(II) Catalysts}

Nagashima developed a novel organoruthenium amidinate $\left\{\left(\eta^{5}-\mathrm{C}_{5} \mathrm{Me}_{5}\right) \mathrm{RuCl}[\eta-i-\mathrm{PrN}=\mathrm{C}(\mathrm{Me}) \mathrm{N}-i-\mathrm{Pr}]\right\}$ (D) that, unlike $\mathrm{RuCl}_{2}\left(\mathrm{PPh}_{3}\right)_{3}$, catalyzes the ATRC of $\mathrm{N}$-vinyltrichloroacetamides and $\mathrm{N}$-allyltrichloroacetamides at room temperature to afford pyrrolidinones, $\beta$-lactams and pyrrolizidines in good yields (Scheme 35 ). ${ }^{45}$
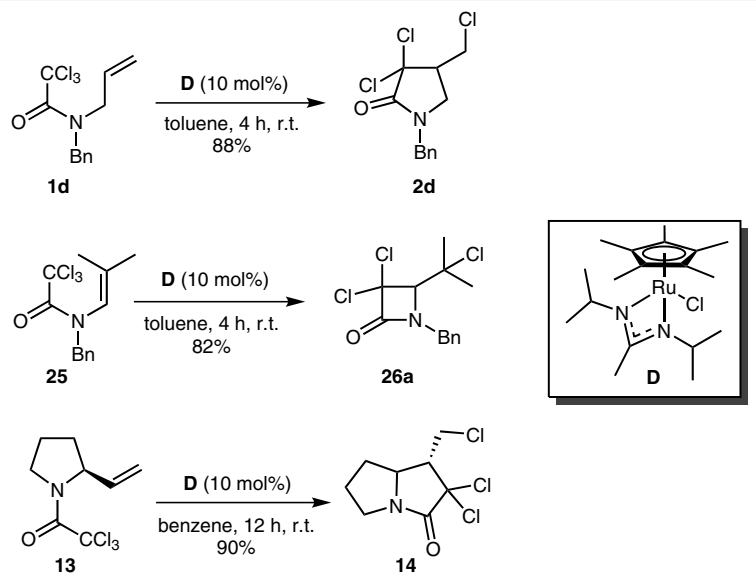

Scheme 35 ATRC-mediated by a novel organoruthenium amidinate

Severin developed a series of bridged ruthenium complexes (E and $\mathbf{F}$ ) able to perform ATRC at room temperature in toluene to afford $\gamma$-lactam $2 \mathbf{i}$ (Scheme 36). ${ }^{46}$

The use of Grubbs' catalysts, known to perform Atom Transfer Radical Addition (ATRA), ${ }^{47}$ was extended by Quayle's group to access $\gamma$-lactams from $N$-allyltrichloroacetamides (Scheme 37). ${ }^{48}$ 


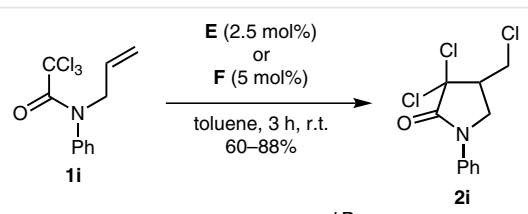

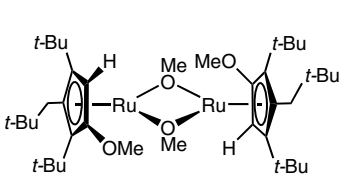

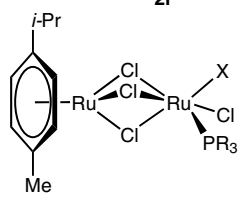

F $\quad \mathrm{X}=\mathrm{Cl}, \mathrm{CH}_{2}=\mathrm{CH}_{2}$ $\mathrm{R}=\mathrm{Cyp}, \mathrm{Cy}$
Scheme 36 ATRC-mediated by bridged Ru(II)-Ru(II) and Ru(II)-Ru(III) complexes

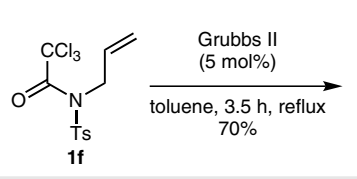<smiles>[12CH3]N1CC(CCl)C(Cl)(Cl)C1=O</smiles><smiles></smiles>

Scheme 37 ATRC promoted by Grubbs' catalyst

Following their work on copper-mediated ATRC (Schemes 27 and 29), Bonjoch's group obtained access to the morphan compound $\mathbf{5 7}$ and 2-azaspiro[4.5]decane $\mathbf{6 7}$ using ATRC-mediated by the Grubbs II catalyst (Scheme 38). ${ }^{49}$ In these reactions a possible SET leading to an oxonium intermediate, instead of an atom-transfer process, may be involved.

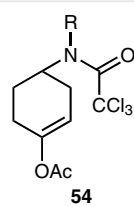

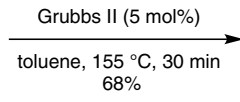

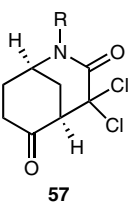<smiles>[2H]Oc1ccc(CNC(=O)C(F)(F)F)cc1</smiles>
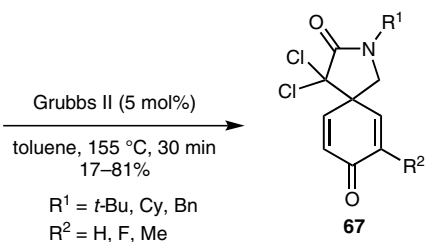

Scheme 38 ATRC of trichloroacetamides mediated by the Grubbs II catalyst

\subsubsection{Tandem Processes}

In 2005, Snapper developed a tandem ruthenium-catalyzed olefin ring-closing metathesis (RCM)-ATRC. ${ }^{50}$ The starting trichloroacetamide $\mathbf{6 8}$ was first treated with the Grubbs I catalyst at room temperature to allow the metathesis to take place, then the temperature was raised to $110{ }^{\circ} \mathrm{C}$ to perform the radical cyclization, leading to $\gamma$-lactams 5 and $\mathbf{6}$. Using the same principle, the tandem reaction was extended to an RCM-ATRC-ATRA, involving styrene in the last step to generate $\gamma$-lactam $\mathbf{6 9}$. These processes constitute one of the high points in the field so far (Scheme 39).

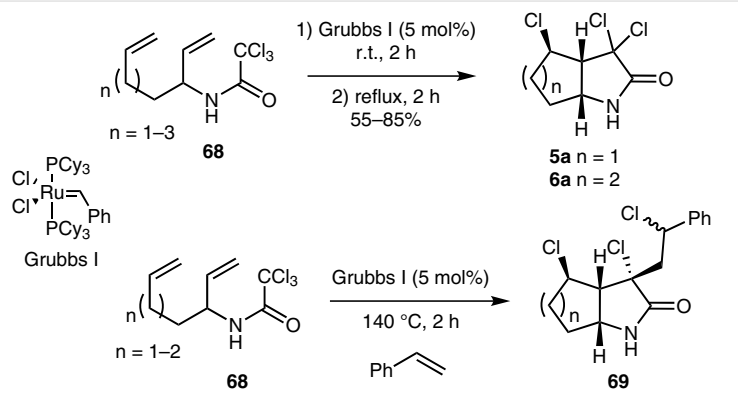

Scheme 39 Bicyclic lactams obtained by RCM-ATRC and RCM-ATRCATRA

Quayle later showed that the Grubbs II catalyst was also able to perform sequential ATRC-ATRA $(\mathbf{1 i} \rightarrow \mathbf{7 0})$ and RCM$\operatorname{ATRC}(\mathbf{6 8 a} \rightarrow \mathbf{5 a})($ Scheme 40$){ }^{51}$

$$
\begin{aligned}
& \text { 2) } 110^{\circ} \mathrm{C}, 3 \mathrm{~d} \\
& \text { 2) }{ }_{22-91 \%}^{22{ }^{\circ}, 2 d} \\
& 68 a \\
& 5 a
\end{aligned}
$$

Scheme 40 Synthesis of $y$-lactams by ATRC-ATRA and RCM-ATRC

Delaude developed a homobimetallic ruthenium-indenylidene complex $\mathbf{G}$, which was able to perform an intramolecular sequential RCM-ATRC from dienes $\mathbf{6 8}$ to give octahydroindoles 6 in good yields (Scheme 41). ${ }^{52}$<smiles>C=CCCCC(C=C)NC(=O)C(Cl)(Cl)Cl</smiles>

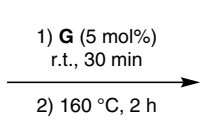

$R=H, 76 \% ; R=B n, 89 \% ; R=T s, 73 \%$<smiles>O=C1N[C@H]2CCCC(Cl)[C@]2(Cl)C1(Cl)Cl</smiles>

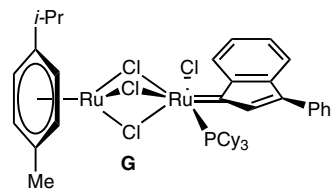

Scheme 41 A new catalyst for the synthesis of $\mathrm{y}$-lactams by RCMATRC

Sutherland developed a one-pot procedure starting from allylic alcohols $\mathbf{7 1}$ to afford bicyclic $\gamma$-lactams 73. The process involved a $\mathrm{Pd}(\mathrm{II})$-mediated Overman rearrange- 
ment leading to trichloroacetamide $\mathbf{7 2}$, followed by a sequential RCM-ATRC mediated by the Grubbs I catalyst (Scheme 42). ${ }^{53}$

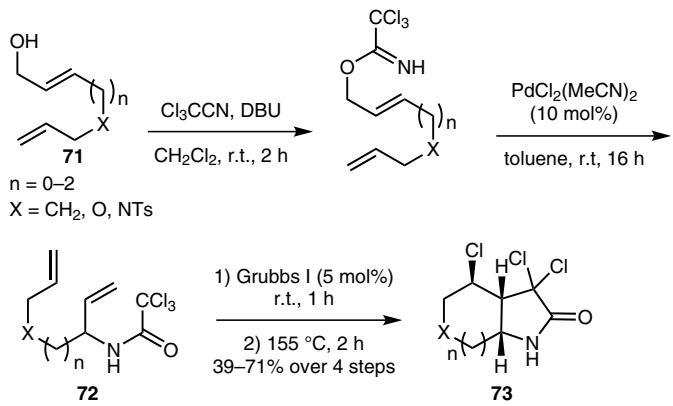

Scheme 42 Synthesis of lactams by an Overman rearrangementRCM-ATRC process

\subsection{ATRC Promoted by Other Metals}

\subsubsection{Iron-Mediated ATRC}

Metals other than copper or ruthenium have been seldom used in atom transfer reactions from trichloroacetamides. As in the case of copper (Scheme 1), the Stauffer Chemical Company were the first to report an iron-mediated ATRC to form a trichloroacetamide. ${ }^{54}$ Using $\mathrm{FeCl}_{2} \cdot 4 \mathrm{H}_{2} \mathrm{O}$, $\mathbf{1 i}$ was heated at reflux in diglyme to afford $\gamma$-lactam $\mathbf{2 i}$ (Scheme 43).

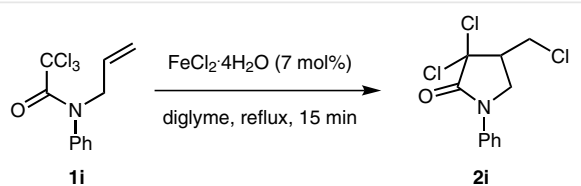

Scheme 43 Iron-mediated ATRC of trichloroacetamides

Ghelfi published the cyclization of $N$-allyltrichloroacetamide 1d using an $\mathrm{Fe}-\mathrm{FeCl}_{3}$ system to generate 2-pyrrolidinone $2 \mathbf{d}$ in good yield. ${ }^{55}$ There are also a few examples of the intermolecular radical addition of $\mathrm{N}$-methyltrichloroacetamide onto non-activated alkenes using $\mathrm{Fe}(0)$ to generate acyclic amides 74 in moderate yield (Scheme 44). ${ }^{56}$

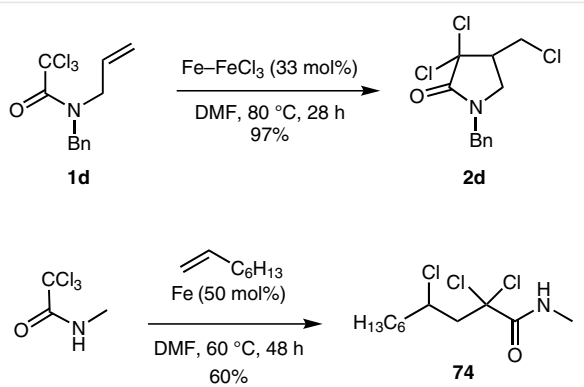

Scheme 44 Iron-catalyzed radical reactions of trichloroacetamides

\subsubsection{Manganese-Mediated ATRC}

Parsons studied the cyclization of trichloroacetamide $\mathbf{1 j}$ to generate pyrrolidinones 75 and 76a using $\mathrm{Mn}_{2}(\mathrm{CO})_{10}$ as a radical promoter and light as a radical initiator (Scheme 45). ${ }^{57}$ The radical ${ }^{\circ} \mathrm{Mn}(\mathrm{CO})_{5}$ is able to abstract halogen atoms from organohalides bearing weak carbon-halogen bonds. The radical formed after the cyclization can be trapped by TEMPO, or reduced by a hydrogen donor such as isopropanol.

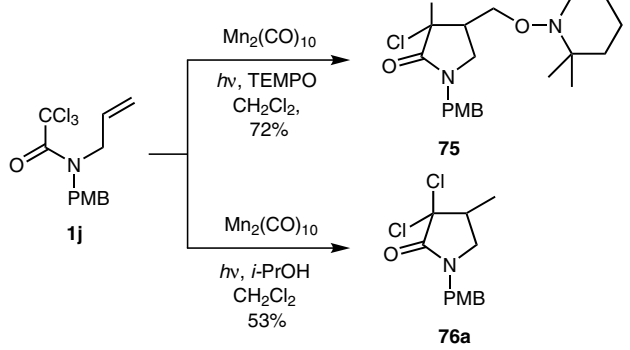

Scheme 45 Mn-catalyzed cyclizations of trichloroacetamides

\section{Photocyclization Reactions}

Another cyclization process from trichloroacetamides through a SET reaction was reported by Moody and coworkers. $^{58}$ Witkop photocyclization ${ }^{59}$ of $\mathrm{N}$-trichloroacetyl tryptophan (77) and related indoles led to azocinoindoles (e.g., 78) (Scheme 46). ${ }^{58}$<smiles>CC(=O)[C@H](Cc1c[nH]c2ccccc12)NC(=O)C(Cl)(Cl)Cl</smiles>

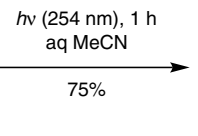

Scheme 46 Photocyclization processes

\section{Reductive Cyclization via Single-Electron Transfer (SET) Processes}

\subsection{Ni/AcOH-Promoted Cyclizations}

Zard introduced metallic nickel in combination with acetic acid, a very weak reducing system, to perform radical cyclization and trapping. These reaction conditions allow the reduction of trichloroacetamides to a transient radical anion, which rapidly expels a chloride anion to generate the dichloromethylcarbamoyl radical that undergoes a cyclization reaction. 
The 5-exo cyclization of $\mathrm{N}$-allyltrichloroacetamides 1d enabled the construction of $\gamma$-lactams, the resulting radical being trapped in numerous ways: hydrogen abstraction from the solvent, or trapping with diphenyl diselenide or cyanide leading to lactams $\mathbf{7 6 b}, \mathbf{7 9}$, and $\mathbf{8 0}$, respectively (Scheme 47).60

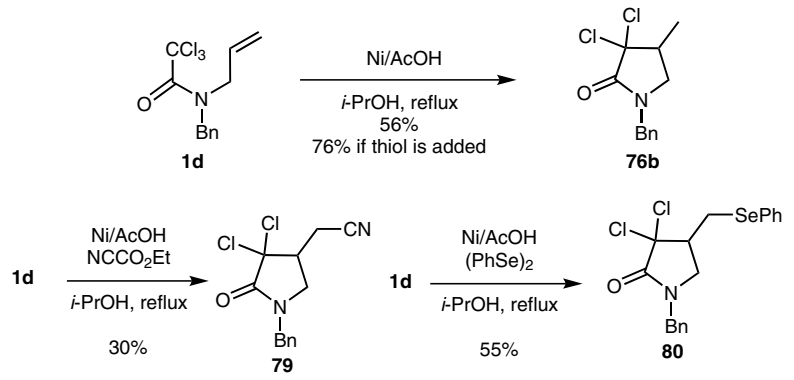

Scheme $47 \mathrm{Ni} / \mathrm{AcOH}$-mediated cyclization of trichloroacetamides

Formation of $\beta$-lactams using a radical process is usually reversible, requiring the introduction of a fast irreversible step, such as a fragmentation followed by a cyclization, to force their formation. In the depicted example in Scheme 48 , the irreversible step consists of the 4-exo cyclization of allylic sulfide $\mathbf{8 1}$, followed by elimination of the benzenethiyl radical to afford $\beta$-lactams 82 in moderate yield. ${ }^{61 a} \mathrm{Al}-$ ternatively, it can consist of a fast intermolecular capture of the tertiary radical intermediate by diphenyl diselenide to give $\mathbf{2 6 b},{ }^{61 b}$ together with small amounts of the 5-endo product 28c.

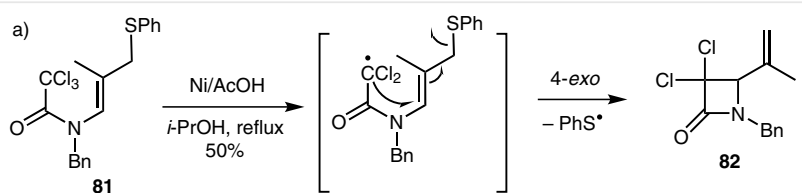

$$
\text { b) }
$$

Scheme $48 \mathrm{Ni} / \mathrm{AcOH}$-mediated cyclization of trichloroenamides

When no trap was added, the only product obtained from trichloroacetamide $\mathbf{2 5}$ arose from the 5-endo cyclization. The radical formed after the cyclization step was easily oxidized to form an acyliminium salt, which was quenched by a chlorine anion and then displaced by the solvent. A further reduction by the $\mathrm{Ni} / \mathrm{AcOH}$ system removed one of the chlorine atoms $\alpha$ to the carbonyl to afford monochlorolactam 83 in moderate yield (Scheme 49). ${ }^{61 \mathrm{~b}}$

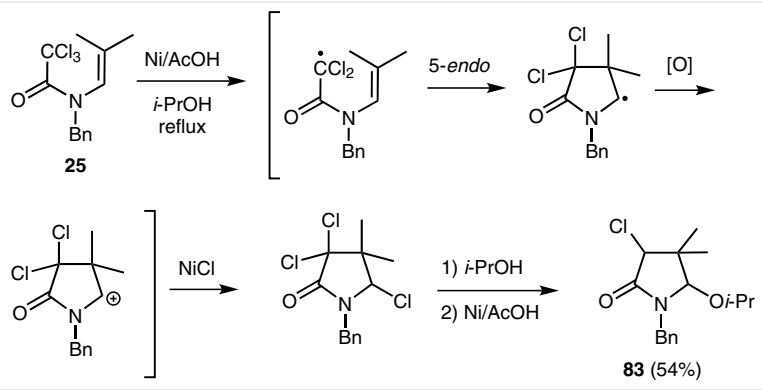

Scheme 49 Synthesis of $\mathrm{y}$-lactams from trichloroenamides

This methodology can be extended to disfavored 5-endo cyclizations of $\mathrm{N}$-alkenyltrichloroacetamides $\mathbf{4}$ to afford unsaturated bicyclic $\gamma$-lactams in moderate to good yields (Scheme 50). ${ }^{61 b}$ In an attempt to trap the product of 4-exo cyclization using diphenyl diselenide, no $\beta$-lactams were observed. The formation of the unsaturated compounds 24a,b and 85a,b could be explained by oxidation of the intermediate radical to a cation, followed by a proton elimination.

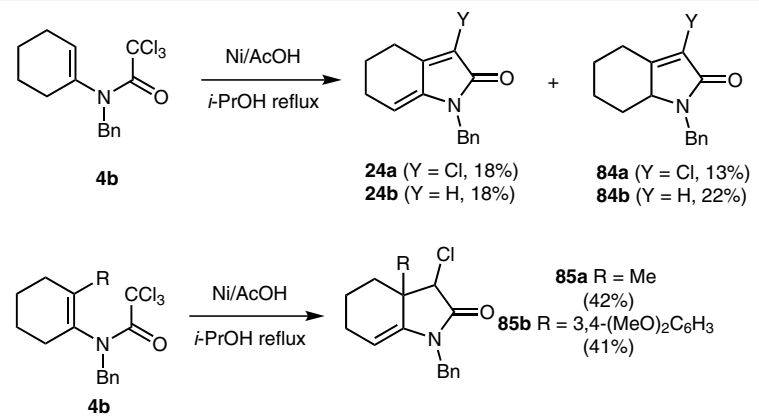

Scheme 50 Synthesis of unsaturated $y$-lactams

Beyond the initial hypothesis that the oxidizing agent of these $\alpha$-amido radicals (see Scheme 49 ) could be the starting trichloroacetamide, Zard demonstrated that cupric ions may have contaminated the nickel batches and could therefore be the source of the oxidation process. In order to confirm this new hypothesis, $\mathrm{Cu}(\mathrm{OAc})_{2}$ was incorporated into the $\mathrm{Ni} / \mathrm{AcOH}$ system and was found to control the oxidation level of the cyclization products of vinylic (5-endo) or allylic (5-exo) trichloroacetamides. ${ }^{62}$ As depicted in Scheme 51, oxidation of trichloroacetamide 86 using the $\mathrm{Ni} / \mathrm{AcOH}$ system yielded the reduced bicyclic lactam $\mathbf{2 4 b}$, whereas addition of $\mathrm{Cu}(\mathrm{OAc})_{2}$ to the reducing system yielded the monochloro derivative $\mathbf{2 4 a}$. 


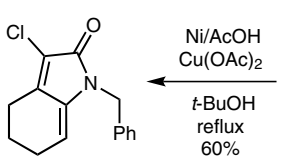

24a

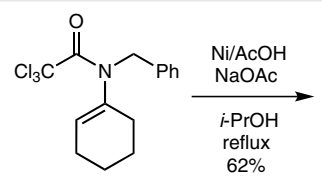

86

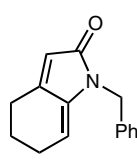

24b
Scheme 51 Oxidation control of bicyclic -lactams

The use of $\mathrm{Ni} / \mathrm{AcOH}$ increases the lifetime of the radical by avoiding its premature reduction. It therefore allowed the 5-exo cyclization of $\mathrm{N}$-aryltrichloroacetamides $\mathbf{8 7}$ (Scheme 52) to afford substituted indolones $\mathbf{8 8}$ in good yields. ${ }^{63}$ The latter are far more difficult to synthesize using classical radical conditions such as tin chemistry.

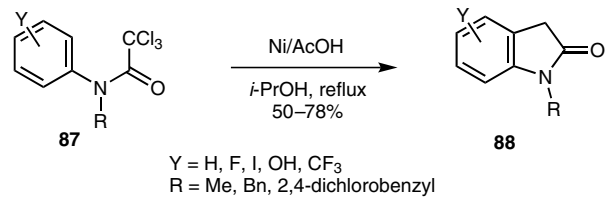

Scheme 52 Ni-promoted trichloromethylanilide cyclization

Taking advantage of the increased lifetime of the radical, the spirocyclization of $N$-benzyltrichloroacetamides $\mathbf{5 2}$ was explored (Scheme 53). ${ }^{64}$ By increasing the bulkiness of the group on the nitrogen, the yields were improved.<smiles>CC(=O)N(Cc1ccccc1)C(C)=O</smiles>

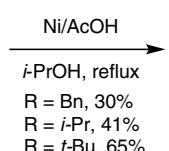

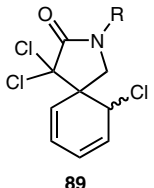

89
Scheme $53 \mathrm{Ni} / \mathrm{AcOH}$-mediated dearomative spirocyclization

This methodology was successfully applied to the total synthesis of erythrina ${ }^{65}$ and lycorane ${ }^{66}$ alkaloids, through the cyclizations $\mathbf{9 0} \rightarrow \mathbf{9 1}$ and $\mathbf{4} \rightarrow \mathbf{9 2}$, respectively, as key steps (Scheme 54).

Interestingly, in sharp contrast with compound 93a, which gave lactam $\mathbf{9 4}$, reaction of $\mathbf{9 3 b}$ under the same conditions afforded enamide 95 (Scheme 55). ${ }^{67}$ Its formation could be explained by a [1,4]-hydrogen atom transfer $(\text { HAT })^{68}$ leading to a stabilized allylic radical, which could further react with diphenyl diselenide.

\subsection{Titanocene(III)-Catalyzed Reactions}

Recently, biscyclopentadienyltitanium(III) chloride $\left(\mathrm{Cp}_{2} \mathrm{TiCl}\right),{ }^{69}$ was introduced to generate dichloromethylcarbamoyl radicals, e.g., for $\mathbf{9 6 a}$, under mild conditions to afford fully reduced lactam $\mathbf{2 8 f}$ (Scheme 56$).{ }^{70} \mathrm{Mn}$ dust and
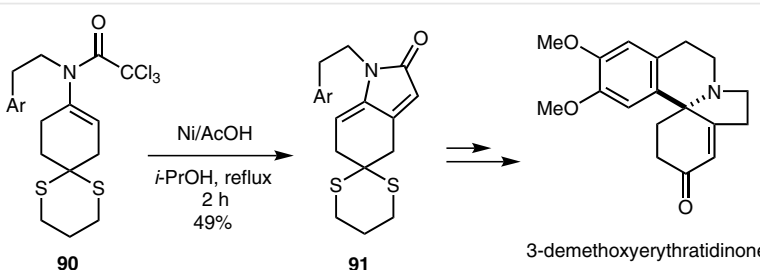

91

3-demethoxyerythratidinone

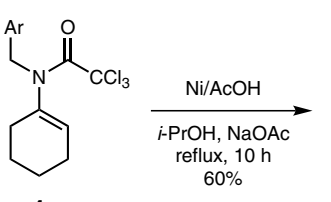

4
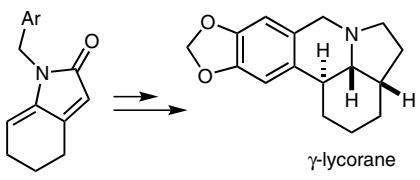

Scheme 54 Synthesis of erythrina and lycorane alkaloids
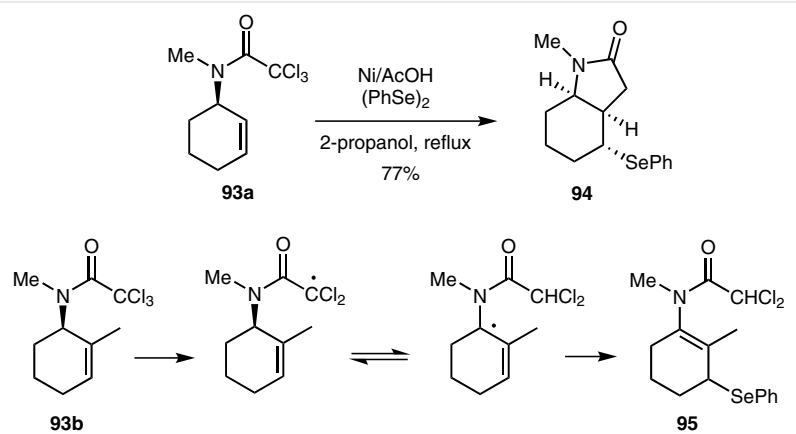

Scheme 55 Effect of steric hindrance on the mode of cyclization

TMSCl/2,4,6-collidine were used to regenerate the titanocene(III) species. The proton source was assumed to be the THF. $^{71}$

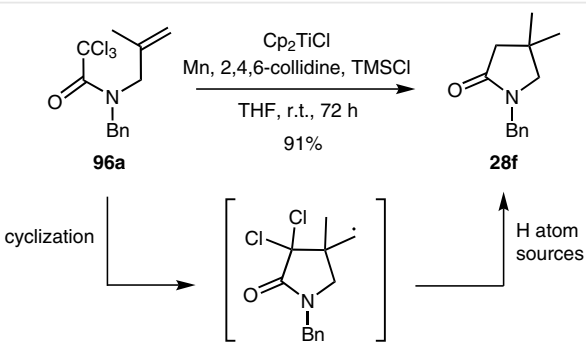

Scheme 56 Ti(III)-mediated radical cyclization

\subsection{Silver Acetate Mediated Reactions}

Also recently, Ueda showed that AgOAc in THF was able to generate radicals to cyclize trichloroacetamide $1 \mathrm{c}$ to afford $\gamma$-lactam 76c in moderate yield (Scheme 57). ${ }^{72}$ It was shown that $\operatorname{Ag}(\mathrm{I})$ was reduced to $\operatorname{Ag}(0)$, which would act as a radical initiator, and THF was again assumed to be the proton source. 
<smiles>C=CCN(CC=C)C(=O)C(Cl)(Cl)Cl</smiles>

$1 c$
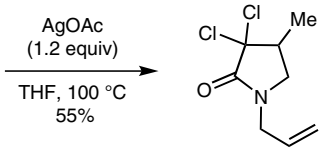

$76 c$
Scheme 57 Ag(0)-mediated radical cyclization

\subsection{Amine-Mediated Single-Electron Transfer}

Following Naito's work, ${ }^{73}$ in which DBU in acetonitrile was found to perform a reductive dechlorination of trichloroacetamides via SET, Ishabashi carried out an extensive screening of amines and found that 1,4-dimethylpiperazine (1,4-DMP) was the best amine to undergo a SET process. ${ }^{74}$ Heating 1,4-dimethylpiperazine and $\mathrm{N}$-allylic or $\mathrm{N}$-vinylic trichloroacetamides $\mathbf{9 6 \mathbf { b }}$ and $\mathbf{4 b}$ yielded substituted pyrrolidinones 28, and bicyclic $\gamma$-lactams 97 (Scheme 58).

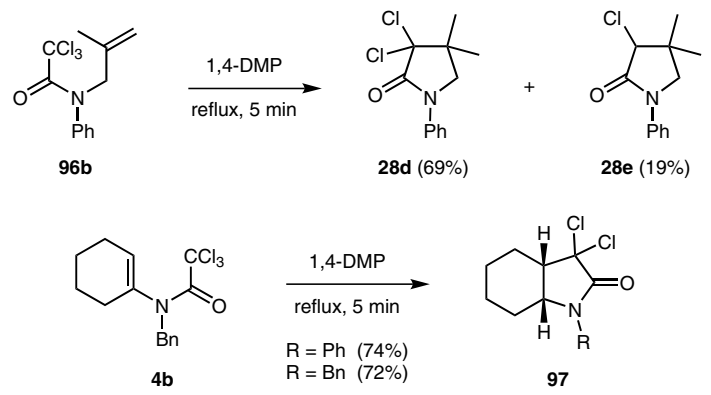

Scheme 58 1,4-DMP-mediated trichloroacetamide cyclization

Cyclization of the electron-rich trichloroacetamide $\mathbf{9 8}$ using the 1,4-DMP-mediated radical cyclization afforded pyrrolizidinone 99, a key intermediate toward the total synthesis of trachelantamidine (Scheme 59). ${ }^{75}$

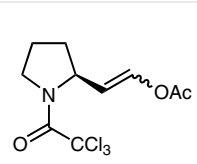

98

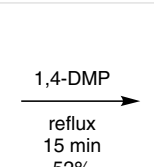

$52 \%$

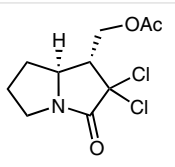

99

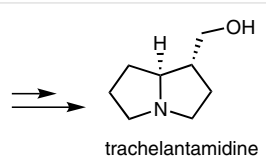

trachelantamidine
Scheme 59 Synthesis of trachelantamidine

Treatment of 0 -ethenyltrichloroacetanilide $\mathbf{1 0 0}$ with 1,4-DMP afforded the unique product 101, through a 6-exo cyclization (Scheme 60). ${ }^{76}$ This methodology showed a higher regioselectivity compared to the $\mathrm{Bu}_{3} \mathrm{SnH}$-mediated reaction (see below).<smiles>C=Cc1ccccc1N(C)C(=O)C(Cl)(Cl)Cl</smiles>
100

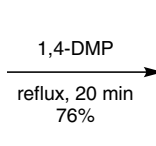

$76 \%$

$$
\text { (2) }
$$

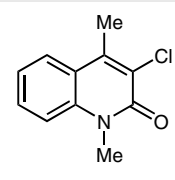

101
Scheme 60 SET-mediated cyclization of trichloroacetanilides
As when using copper (Scheme 26), Clark employed 1,4DMP to demonstrate that in sulfonamides $\mathbf{5 0}$, in the absence of a radical acceptor, 1,4-aryl transfer took place leading to $\mathrm{N}$-alkyldichloroarylacetamides 51 (Scheme 61). ${ }^{35 a}$

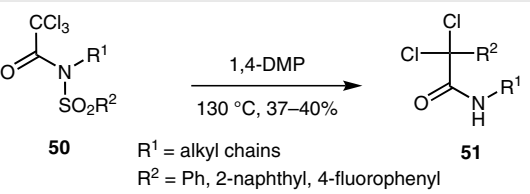

Scheme 61 1,4-DMP-mediated aryl migration

When tackling the problem of reproducibility, Ishibashi and co-workers figured out that water plays a key role in the SET process. ${ }^{77}$ When distilled 1,4-DMP was used, the reaction worked poorly, resulting mainly in the decomposition of 102. By adding up to five equivalents of water, the reproducibility of the cyclization was recovered to afford 103 (Scheme 62). Adding additional water led to a drop in the yield.

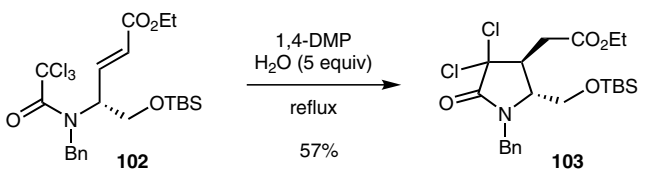

Scheme 62 Effect of water on the 1,4-DMP-mediated radical cyclization

\section{Cyclization Involving M-H Hydrogen Atom Donors (M = Sn, Si, B)}

\section{1 $\mathrm{Bu}_{3} \mathrm{SnH}$-Mediated Reactions}

Yamazaki's group described the first example of piperidine ring formation by a radical reductive procedure in the synthesis of benzo[a]quinolizidine 104. The starting material, trichloroacetamide 11, bore an alkene with an electron-withdrawing group as the radical acceptor (Scheme 63). ${ }^{10}$
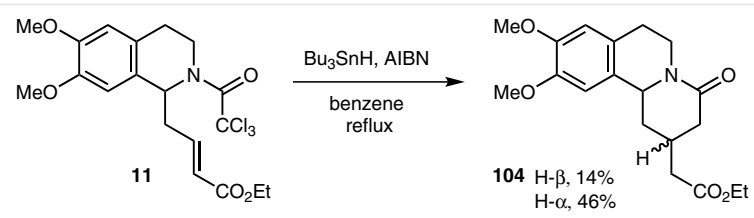

Scheme 63 Tin-mediated piperidine formation

Parsons studied the 5-exo cyclization of serine-derived trichloroacetamides $\mathbf{1 0 5}$ and obtained trisubstituted pyrrolidinones $\mathbf{1 0 6}$ as intermediates toward the synthesis of kainoid amino acids (Scheme 64). ${ }^{78}$ 
<smiles>[2H]N(C(=O)O)C(C=CC(=O)OCC)CO[GaH2]</smiles>

$$
\begin{aligned}
& \stackrel{\mathrm{Bu}_{3} \mathrm{SnH}, \text { AlBN }}{\text { benzene, reflux }} \\
& \begin{array}{l}
\mathrm{R}=\mathrm{H}, 61 \% \\
\mathrm{R}=\mathrm{Bn}, 77 \% ; 29: 71 \text { cis/trans }
\end{array}
\end{aligned}
$$$$
\sum_{\mathrm{H}}^{\mathrm{CO}_{2} \mathrm{H}}
$$

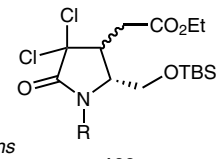

106

$$
\text { kainoids }
$$

Scheme 64 Toward kainoid amino acids

The 4-substituted pyroglutamate $\mathbf{1 0 7}$ was obtained in a disfavored 5-endo tin-mediated cyclization of serinederived $\mathrm{N}$-trichloroacetamido dehydroalanine 38a (Scheme $65)^{79}$

$$
\text { benzene, reflux }
$$

Scheme 65 Synthesis of pyroglutamates

Ishibashi et al. studied the factors influencing the cyclization mode (4-exo or 5-endo) of trichloroacetamide 108. ${ }^{80}$ The 4-exo process was predominant when the $\mathrm{N}$-vinylic bond was substituted with a phenylthio group, which increased the stability of the formed radical. However, the main factor influencing the course of the reaction was the temperature. As depicted in Scheme 66, when the cyclization of trichloroacetamide $\mathbf{1 0 8}$ was carried out at reflux in toluene, the only isolated product was the $\gamma$-lactam 24a, whereas at room temperature (with triethylborane as the radical initiator), the 4-exo product 109 was obtained, albeit in low yield. At low temperatures (kinetic conditions), the dichloromethylcarbamoyl radical cyclizes predominantly in a 4-exo fashion. However, at a high temperature, ring opening occurs rapidly and the resulting radical cyclizes in a 5endo manner. When the enamide was substituted by a phenyl (i.e., $\mathbf{4 b}$ ) instead of a thiophenyl group, no product of 4exo cyclization was detected because the intermediate radical was insufficiently stabilized by the aromatic $\pi$-system due to its free rotation (Scheme 66, b). ${ }^{80 \mathrm{~b}}$

Interestingly, the trichloroacetamide 111, upon treatment with $\mathrm{Bu}_{3} \mathrm{SnH}$ (1.2 equiv) and $\mathrm{AIBN}$, gave the aromatized product 112, whereas the dichloroacetamide (not shown) provided the $\beta$-lactam. ${ }^{80 \mathrm{c}}$ It was assumed that the aromatization took place by a non-radical process involving dehydrochlorination from an initially formed dichlorolactam (Scheme 67). a)
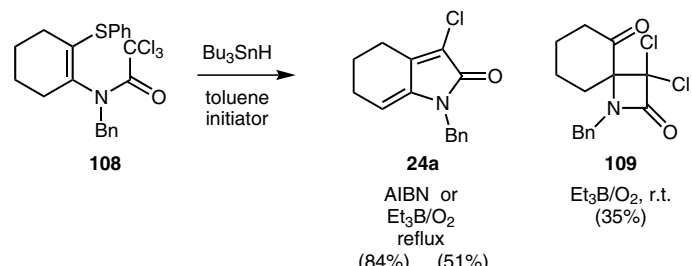

109

$\mathrm{Et}_{3} \mathrm{~B} / \mathrm{O}_{2}$, r.t.

(35\%)

b)

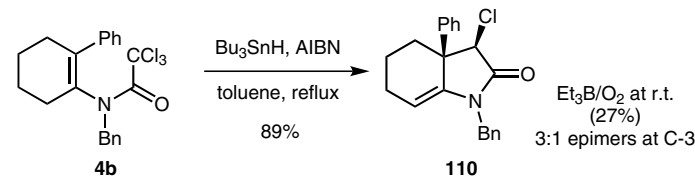

Scheme 66 The 4-exo vs 5-endo cyclization of trichloroacetamides<smiles>O=C(N(P)C1=Cc2ccccc2[CH+]C1)C(Cl)(Cl)Cl</smiles>

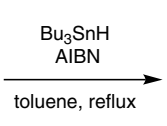

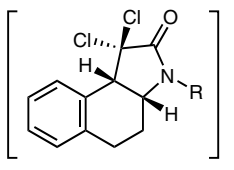

$R=M e, 40 \%$
$R=B n, 53 \%$
Scheme 67 Synthesis of benzo[e]indoles

In 1997, a series of studies on the synthesis of 2-azabicyclo[3.3.1]nonanes via reductive radical-triggered 6-exotrig carbocyclizations was carried out by Bonjoch's group (see section 5.2). Using $\mathrm{Bu}_{3} \mathrm{SnH}$ methodology to perform 6exo cyclization upon electron-rich alkenes 54 afforded morphans 113 (Scheme 68). ${ }^{81}$
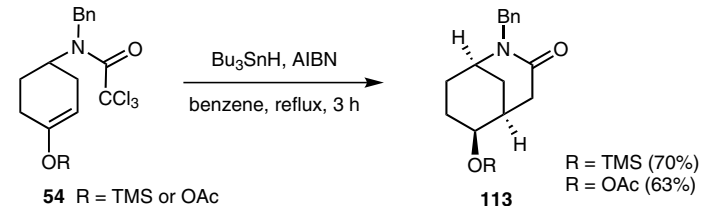

Scheme 68 Synthesis of morphans

The enantiopure trichloroacetamides $\mathbf{1 1 4}$ were submitted to a tin-mediated radical cyclization to afford the desired morphans 115 together with the normorphans 116 in a stereospecific manner (Scheme 69). ${ }^{82}$ The formation of the normorphans could be explained by $1,4-\mathrm{HAT}^{68}$ with memory of chirality (MOC) ${ }^{83}$ due to the high activation barrier for rotation of the $\mathrm{C}-\mathrm{N}$ single bond, which preserves its absolute chirality during the course of the reaction. Latterly, the radical cyclization has been studied using $\mathrm{CuCl} / \mathrm{TMPA} / \mathrm{AIBN}$ (as in Scheme 29), with similar results. ${ }^{84}$

Another intramolecular tin-mediated 6-exo radical cyclization occurred using trichloroacetamides $\mathbf{1 1 7}$ with an $\alpha, \beta$-unsaturated ketone as a radical acceptor to generate 
<smiles>CC(=O)N(C(c1ccccc1)c1ccccc1)C(C)(C)C</smiles>

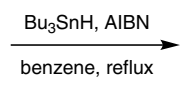<smiles>C[C@H](O)[C@@H]1C[C@@H](C#N)CC[C@H]1C#N</smiles><smiles>CC(C)[C@@H]1CCCCN1C</smiles>
$\overline{\bar{C}} \mathrm{~N}$ $116 \mathrm{a}(20 \%)$<smiles>N#CC1=CCC2CC1CCC2N(C(=O)[O-])c1ccccc1</smiles>
$\underset{\text { benzene, reflux }}{\stackrel{\mathrm{Bu}_{3} \mathrm{SnH}, \mathrm{AlBN}}{\longrightarrow}}$ $115 \mathrm{a}(44 \%)$

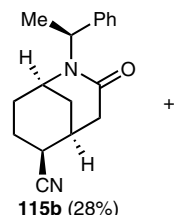

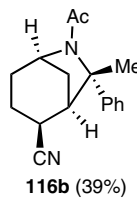

Scheme 69 Synthesis of enantiopure morphans

cis-hydroisoquinolines 118 (Scheme 70). ${ }^{85}$ Comparable yields for this radical cyclization were found using $\left(\mathrm{Me}_{3} \mathrm{Si}\right)_{3} \mathrm{SiH}$ (see section 5.2).<smiles>CC(=O)NCC1C=CC(=O)CC1</smiles>

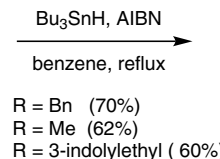

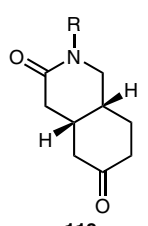

118
Scheme 70 Tin-mediated synthesis of cis-hydroisoquinolines

Trichloroacetamide 119, bearing a cyclohexenylmethyl substituent, was cyclized in a 5-exo fashion to afford spirolactam 120 (Scheme 71). ${ }^{86}$
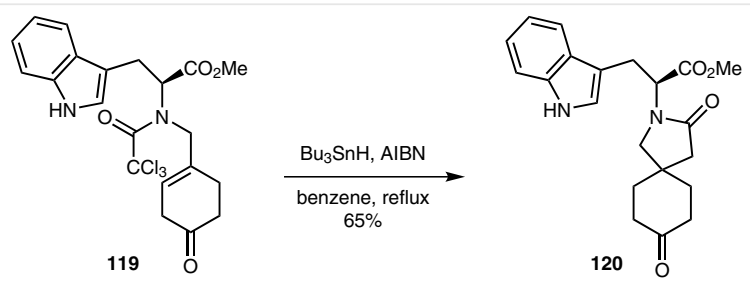

Scheme 71 Tin-mediated synthesis of spirolactams

Ishibashi studied the $\mathrm{Bu}_{3} \mathrm{SnH}$-mediated cyclization of 0 ethenyltrichloroacetanilide 100, which led to a mixture of 6-exo cyclization products 121 and 122 (Scheme 72). ${ }^{76}$ Formation of the latter was assumed to go through a neophyl rearrangement of a radical intermediate and not through a 7-endo cyclization process.<smiles>C/C=C\c1ccccc1N(C(=O)C(C)(C)C)C(=O)C(Cl)(Cl)Cl</smiles>

100

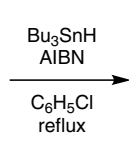

reflux

(1)

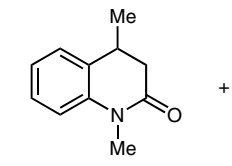

$121(32 \%)$

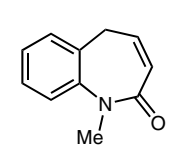

$122(25 \%)$
Scheme 72 Tin-mediated cyclization of o-ethenyltrichloroacetanilides

\section{$5.2\left(\mathrm{Me}_{3} \mathrm{Si}\right)_{3} \mathrm{SiH}$ (TTMSS)-Mediated Reactions}

Bonjoch's group introduced $\left(\mathrm{Me}_{3} \mathrm{Si}\right)_{3} \mathrm{SiH}$ to generate dichloromethylcarbamoyl radicals. These underwent cyclization onto non-activated $(\mathrm{R}=\mathrm{H}){ }^{87}$ electron-rich $(\mathrm{R}=\mathrm{OAc}$, OTMS $)^{81,88}$ or electron-poor $\left(\mathrm{R}=\mathrm{CN}, \mathrm{CO}_{2} \mathrm{Me}\right)^{89}$ alkenes $\mathbf{5 4}$, affording morphans 123 and 124 (Scheme 73). The wide scope of this reaction is explained by the ambiphilic character of the dichloromethylcarbamoyl radical, which acts as a nucleophile with electron-poor alkenes, behaving as an equivalent of a $\beta$-aminocarbanion. On the other hand, with electron-rich alkenes, it acts as an electrophile, serving as an equivalent of a $\beta$-aminocarbocation. Together with the benzo[ $a]$ quinolizidine synthesis previously described by Yamazaki $^{10}$ (Scheme 63), these results expanded the scope of six-membered ring formation using trichloroacetamides with a reductive method.<smiles>[R]C1=CCC(N(Cc2ccccc2)C(=O)C(Cl)(Cl)Cl)CC1</smiles>
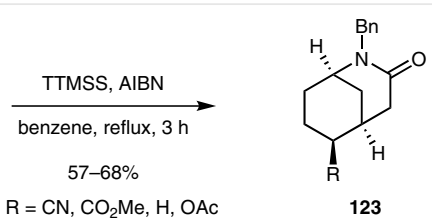<smiles>COC1=CCC(N(Cc2ccccc2)C(=O)C(Cl)(Cl)Cl)CC1</smiles>

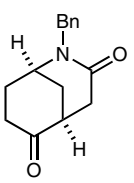

124

Scheme 73 Synthesis of 6-functionalized morphans

This methodology was applied in the synthesis of the alkaloids melinonine $\mathrm{E}$ and strychnoxanthine (Scheme 74). ${ }^{90}$ In a one-pot procedure, trichloroacetamide 125, embodying all the carbon atoms of the targeted alkaloids, was treated with $\left(\mathrm{Me}_{3} \mathrm{Si}\right)_{3} \mathrm{SiH}$ to perform the radical cyclization, followed by the addition of $\mathrm{Bu}_{3} \mathrm{SnH}$ to reduce the remaining chlorine atoms, leading to amide $\mathbf{1 2 6 .}$

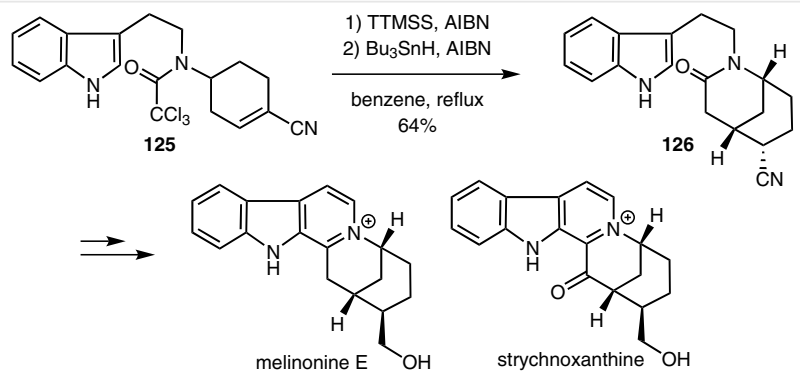

Scheme 74 Total synthesis of melinonine E and strychnoxanthine

In the depicted example (Scheme 75), silyl enol ethers $127^{82 \mathrm{~b}, 91}$ were submitted to the $\left(\mathrm{Me}_{3} \mathrm{Si}\right)_{3} \mathrm{SiH}$-mediated radical cyclization to afford enantiopure morphans 128 togeth- 

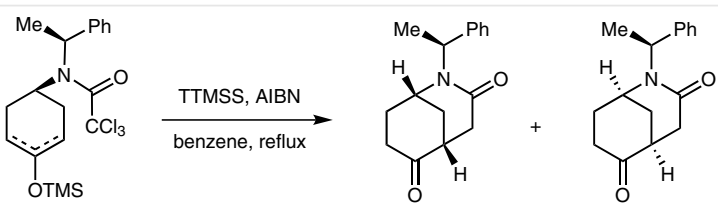

128a $(10 \%)$

128b (21\%)
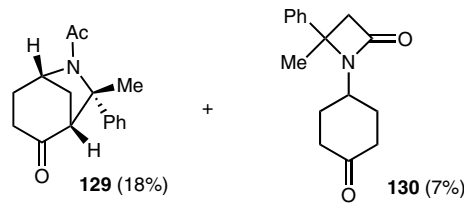

Scheme 75 Synthesis of enantiopure morphans

er with two by-products, normorphan 129 and $\beta$-lactam 130.

Recently, Bonjoch and co-workers described a radical cyclization of trichloroacetamide-tethered ketone 131 using pyrrolidine, AIBN and TTMSS under microwave activation, leading to 2-azabicyclo[3.3.1]nonan-3,6-dione 124. In a five-minute one-pot process, after the generation of an enamine, intramolecular addition of a dichloromethylcarbamoyl radical, and oxidation of the $\alpha$-aminoalkyl radical intermediate, the resulting iminium salt evolved into the corresponding enamine and, after work-up, into ketone $\mathbf{1 2 4}$ (Scheme 76). ${ }^{92}$<smiles>O=C1CCC(N(Cc2ccccc2)C(=O)C(Cl)(Cl)Cl)CC1</smiles>

131

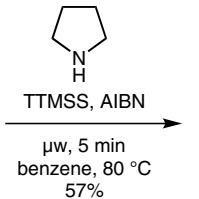

$57 \%$
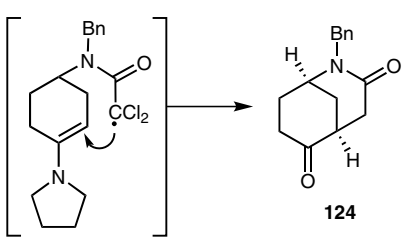

124

Scheme 76 One-pot radical cyclization of a trichloroacetamide via an enamine

\subsection{Borohydride-Mediated Radical Cyclizations}

Following the early work of Barltrop ${ }^{93}$ and the more recent studies of Ryu ${ }^{94}$ Bonjoch's group investigated the use of $\mathrm{NaBH}_{3} \mathrm{CN}$ for radical cyclization involving trichloroacetamides. In an initial synthesis of the morphan ring system 132, the 6-exo-trig radical cyclization proceeded smoothly in tert-butanol using AIBN as the radical initiator and sodium cyanoborohydride as the source of hydrogen to trap the radical intermediate after the radical cyclization step. The $\mathrm{BH}_{2} \mathrm{CN}$ radical anion also allows the radical chain mechanism through a carbon-chlorine homolytic cleavage in the starting trichloroacetamide $\mathbf{5 4}$. Thus, after an additional reduction, the morphan 132 was isolated in 85\% yield (Scheme 77). ${ }^{95}$ It should be noted that the cyanoborane radical anion $\left(\mathrm{BH}_{2} \mathrm{CN}^{-}\right)$did not reduce the last chlorine atom.

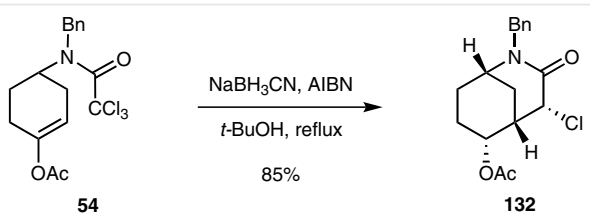

Scheme $77 \mathrm{NaBH}_{3} \mathrm{CN}$-mediated radical cyclization

\section{Concluding Remarks}

The chemistry associated with trichloro derivatives as a source of C-centered radicals is more extensive than the trichloroacetamide-based research covered here and studies on trichloroethylamines, ${ }^{96}$ trichloromethyl ketones, ${ }^{97}$ and trichloroacetates ${ }^{98}$ have been reported. Moreover, the use of dichloro- and monochloroacetamides, also well established, gives different results compared with their trichloro analogs reported here.

In conclusion, trichloroacetamides are radical precursors that allow a wide range of radical cyclizations in a vast array of procedures, including atom transfer, single-electron transfer and hydride-mediated reactions. The efficiency of trichloroacetamides in these radical processes could be related with the electrophilicity of the carbamoyldichloromethyl radical and a low energy barrier for the rotation around the $\mathrm{C}-\mathrm{N}$ amide bond.

The radical cyclization of trichloroacetamides represents a unique approach for lactam formation with the generation of a $\mathrm{C}-\mathrm{C}$ bond. Despite its simplicity, this reaction is important in terms of its synthetic applications. Among the resulting compounds, which are either polychlorinated or fully reduced, are $\beta-, \gamma-$, and $\delta$-lactams. These represent highly useful building blocks in the synthesis of nitrogen-containing natural products and bioactive molecules.

\section{Acknowledgment}

Financial support was provided by FP7 Marie Curie Actions of the European Commission via the ITN ECHONET Network (MCITN-2012316379). We also thank MINECO (Spain) for its support of our programs (CTQ2013-41338-P). We appreciate the constructive comments of the reviewers.

\section{References}

(1) Present Address: Uriach, Avgda Camí Reial 51-57, 08184 Palausolità i Plegamans, Barcelona (Spain).

(2) (a) Clark, A. J. Chem. Soc. Rev. 2002, 31, 1. (b) Eckenhoff, W. T.; Pintauer, T. Catal. Rev. 2010, 52, 1. (c) Pintauer, T. Eur. J. Inorg. Chem. 2010, 2449. (d) Clark, A. J. Eur. J. Org. Chem. 2016, 2231.

(3) Giese, B.; Kopping, B.; Göbel, T.; Dickhaut, J.; Thoma, G.; Kulicke, K. J.; Trach, F. Org. React. 1995, 48, 301. 
(4) (a) Broggi, J.; Terme, T.; Vanelle, P. Angew. Chem. Int. Ed. 2014, 53, 384. (b) Zhang, N.; Samanta, S. R.; Rosen, B. M.; Percec, V. Chem. Rev. 2014, 114, 5848.

(5) For selected books on radicals in organic synthesis, see: (a) Radicals in Organic Synthesis; Vol. 2; Renaud, P.; Sibi, M. P., Eds.; Wiley-VCH: Weinheim, 2001. (b) Togo, H. Advanced Free Radical Reactions for Organic Synthesis; Elsevier: Amsterdam, 2003. (c) Zard, S. Z. Radical Reactions in Organic Synthesis; Oxford University Press: Oxford, 2003.

(6) Nagashima, H.; Wakamatsu, H.; Itoh, K. J. Chem. Soc., Chem. Commun. 1984, 652.

(7) For a comprehensive review, see: Overman, L. E.; Carpenter, N. E. In Organic Reactions; Overman, L. E., Ed.; Hoboken: Wiley, 2005, 661.

(8) Broadhurst, M. D. US Patent 4132713, 1977.

(9) Nagashima, H.; Ara, K.-I.; Wakamatsu, H.; Itoh, K. J. Chem. Soc., Chem. Commun. 1985, 518.

(10) Hirai, Y.; Hagiwara, A.; Terada, T.; Yamazaki, T. Chem. Lett. 1987, 2417.

(11) Seijas, J. A.; Vázquez-Tato, M. P.; Castedo, L.; Estévez, R. J.; Ónega, M. G.; Ruíz, M. Tetrahedron 1992, 48, 1637.

(12) Pattarozzi, M.; Roncaglia, F.; Giangiordano, V.; Davoli, P.; Prati, F.; Ghelfi, F. Synthesis 2010, 694.

(13) Cornia, A.; Felluga, F.; Frenna, V.; Ghelfi, F.; Pagnoni, U. M.; Parsons, A. F.; Petrillo, G.; Spinelli, D. Synthesis 2011, 8, 1267.

(14) (a) Nagashima, H.; Ozaki, N.; Seki, K.; Ishii, M.; Itoh, K. J. Org. Chem. 1989, 54, 4497. (b) Nagashima, H.; Ozaki, N.; Ishii, M.; Seki, K.; Washiyama, M.; Itoh, K. J. Org. Chem. 1993, 58, 464.

(15) Iwamatsu, S.-I.; Matsubara, K.; Nagashima, H. J. Org. Chem. 1999, 64, 9625.

(16) For steric and electronic influences of the $\mathrm{N}$-substituent on the ratio of rotamers, see: (a) Stork, G.; Mah, R. Heterocycles 1989, 28, 723. (b) Bartuschat, A. L.; Wicht, K.; Heinrich, M. R. Angew. Chem. Int. Ed. 2015, 54, 10294. (c) Clark, A. J.; Curran, D. P.; Fox, D. J.; Ghelfi, F.; Guy, C. S.; Hay, B.; James, N.; Phillips, J. M.; Roncaglia, F.; Sellars, P. B.; Wilson, P.; Zhang, H. J. Org. Chem. 2016, 81, 5547.

(17) Iwamatsu, S.-I.; Kondo, H.; Matsubara, K.; Nagashima, H. Tetrahedron 1999, 55, 1687.

(18) For radical domino reactions in organic synthesis, see: Sebre, L. J.; Devery, J. J. III; Stephenson, C. R. J. ACS Catal. 2014, 4, 703.

(19) (a) Davies, D. T.; Kapur, N.; Parsons, A. F. Tetrahedron Lett. 1999, 40, 8615. (b) Davies, D. T.; Kapur, N.; Parsons, A. F. Tetrahedron 2000, 56, 3941.

(20) Bryans, J. S.; Chessum, N. E. A.; Parsons, A. F.; Ghelfi, F. Tetrahedron Lett. 2001, 42, 2901.

(21) Bryans, J. S.; Chessum, N. E. A.; Huther, N.; Parsons, A. F.; Ghelfi, F. Tetrahedron 2003, 59, 6221.

(22) (a) Benedetti, M.; Forti, L.; Ghelfi, F.; Pagnoni, U. M.; Ronzoni, R. Tetrahedron 1997, 14031. (b) Ghelfi, F.; Bellesia, F.; Ghirardini, G.; Grandi, R.; Libertini, E.; Montemaggi, M. C.; Pagnoni, U. M.; Pinetti, A.; De Buyck, L.; Parsons, A. F. Tetrahedron 1999, 55, 5839. (c) Pattarozzi, M.; Roncaglia, F.; Accorsi, L.; Parsons, A. F.; Ghelfi, F. Tetrahedron 2010, 66, 1357.

(23) Ghelfi, F.; Parsons, A. F. J. Org. Chem. 2000, 65, 6249.

(24) Bregoli, M.; Felluga, F.; Frenna, V.; Ghelfi, F.; Parsons, A. F.; Pattarozzi, M.; Roncaglia, F.; Spinelli, D. Tetrahedron 2012, 68, 5863.

(25) (a) Stevens, C. V.; Van Meenen, E.; Eeckhout, Y.; Vanderhoydonck, B.; Hooghe, W. Chem. Commun. 2005, 4827. (b) Stevens, C. V.; Van Meenen, E.; Masschelein, K. G. R.; Eeckhout, Y.; Hooghe, W.; D'hondt, B.; Nemykin, V. N.; Zhdankin, V. Z. Tetrahedron Lett. 2007, 48, 7108.
(26) (a) Clark, A. J.; Filik, R. P.; Haddleton, D. M.; Radigue, A.; Sanders, C. J.; Thomas, G. H.; Smith, M. E. J. Org. Chem. 1999, 64, 8954. (b) Clark, A. J.; Geden, J. V.; Thom, S. J. Org. Chem. 2006, 71, 1471.

(27) Clark, A. J.; Dell, C. P.; Ellard, J. M.; Hunt, N. A.; McDonagh, J. P. Tetrahedron Lett. 1999, 40, 8619.

(28) Clark, A. J.; Battle, G. M.; Heming, A. M.; Haddleton, D. M.; Bridge, A. Tetrahedron Lett. 2001, 42, 2003.

(29) Motoyama, Y.; Kamo, K.; Yuasa, A.; Nagashima, H. Chem. Commun. 2010, 46, 2256.

(30) Clark, A. J.; De Campo, F.; Deeth, R. J.; Filik, R. P.; Gatard, S.; Hunt, N. A.; Lastécouères, D.; Thomas, G. H.; Verlhac, J.; Wongtap, H. J. Chem. Soc., Perkin Trans. 1 2000, 671.

(31) Geden, J. V.; Clark, A. J.; Coles, S. R.; Guy, C. S.; Ghelfi, F.; Thom, S. Tetrahedron Lett. 2016, 57, 3109.

(32) Clark, A. J.; Geden, J. V.; Thom, S.; Wilson, P. J. Org. Chem. 2007, 72, 5923.

(33) Ram, R. N.; Soni, V. K. Adv. Synth. Catal. 2016, 358, 276.

(34) Bull, J. A.; Hutchings, M. G.; Luján, C.; Quayle, P. Tetrahedron Lett. 2008, 49, 1352.

(35) (a) Clark, A. J.; Coles, S. R.; Collis, A.; Debure, T.; Guy, C.; Murphy, N. P.; Wilson, P. Tetrahedron Lett. 2009, 50, 5609. (b) Clark, A. J.; Coles, S. R.; Collis, A.; Fullaway, D. R.; Murphy, N. P.; Wilson, P. Tetrahedron Lett. 2009, 50, 6311.

(36) Diaba, F.; Montiel, J. A.; Martinez-Laporta, A.; Bonjoch, J. Tetrahedron Lett. 2013, 54, 2619.

(37) (a) Pintauer, T.; Matyjaszewski, K. Chem. Soc. Rev. 2008, 37, 1087. (b) Balili, M. N. C.; Pintauer, T. Inorg. Chem. 2010, 49, 5642.

(38) Clark, A. J.; Duckmanton, J. N.; Felluga, F.; Gennaro, A.; Ghelfi, F.; Hardiman, J. R. D.; Isse, A. A.; Manferdini, C.; Spinelli, D. Eur. J. Org. Chem. 2016, 2479.

(39) (a) Casaroli, R.; Felluga, F.; Frenna, V.; Ghelfi, F.; Pagnoni, U. M.; Parsons, A. F.; Spinelli, D. Tetrahedron 2011, 67, 408. (b) Bellesia, F.; Clark, A. J.; Felluga, F.; Gennaro, A.; Isse, A. A.; Roncaglia, F.; Ghelfi, F. Adv. Synth. Catal. 2013, 355, 1649. (c) Clark, A. J.; Cornia, A.; Felluga, F.; Gennaro, A.; Ghelfi, F.; Isse, A. A.; Menziani, M. C.; Muniz-Miranda, F.; Roncaglia, F.; Spinelli, D. Eur. J. Org. Chem. 2014, 6734.

(40) (a) Diaba, F.; Martínez-Laporta, A.; Bonjoch, J.; Pereira, A.; Muñoz-Molina, J. M.; Pérez, P. J.; Belderrain, T. R. Chem. Commun. 2012, 8799. (b) Diaba, F.; Martínez-Laporta, A.; Coussanes, G.; Fernández, I.; Bonjoch, J. Tetrahedron 2015, 71, 3642.

(41) Nagashima, H.; Wakamatsu, H.; Ozaki, N.; Ishii, T.; Watanabe, M.; Tajima, T.; Itoh, K. J. Org. Chem. 1992, 57, 1682.

(42) Rachita, M. A.; Slough, G. A. Tetrahedron Lett. 1993, 34, 6821.

(43) Swift, M. D.; Donaldson, A.; Sutherland, A. Tetrahedron Lett. 2009, 50, 3241.

(44) Li, Q.; Li, G.; Ma, S.; Feng, P.; Shi, Y. Org. Lett. 2013, 15, 2601.

(45) (a) Nagashima, H.; Gondo, M.; Masuda, S.; Kondo, H.; Yamaguchi, Y.; Matsubara, K. Chem. Commun. 2003, 442. (b) Motoyama, Y.; Hanada, S.; Shimamoto, K.; Nagashima, H. Tetrahedron 2006, 62, 2779.

(46) (a) Dutta, B.; Scopelliti, R.; Severin, K. Organometallics 2008, 27, 423. (b) Wolf, J.; Thommes, K.; Briel, O.; Scopelliti, R.; Severin, K. Organometallics 2008, 27, 4464.

(47) Tallarico, J. A.; Malnick, L. M.; Snapper, M. L. J. Org. Chem. 1999, $64,344$.

(48) Quayle, P.; Fengas, D.; Richards, S. Synlett 2003, 1797.

(49) Diaba, F.; Martínez-Laporta, A.; Bonjoch, J. J. Org. Chem. 2014, 79, 9365.

(50) Seigal, B. A.; Fajardo, C.; Snapper, M. L. J. Am. Chem. Soc. 2005, $127,16329$. 
(51) Edlin, C. D.; Faulkner, J.; Quayle, P. Tetrahedron Lett. 2006, 47, 1145.

(52) Borguet, Y.; Sauvage, X.; Zaragoza, G.; Demonceau, A.; Delaude, L. Beilstein J. Org. Chem. 2010, 6, 1167.

(53) (a) McGonagle, F. I.; Brown, L.; Cooke, A.; Sutherland, A. Org. Biomol. Chem. 2010, 8, 3418. (b) McGonagle, F. I.; Brown, L.; Cooke, A.; Sutherland, A. Tetrahedron Lett. 2011, 52, 2330.

(54) (a) Gordon E.; DE2612731A1, 1976. (b) Gordon E.; FR2305434A1, 1976.

(55) Benedetti, M.; Forti, L.; Ghelfi, F.; Pagnoni, U. M.; Ronzoni, R. Tetrahedron 1997, 53, 14031.

(56) Forti, L.; Ghelfi, F.; Libertini, E.; Pagnoni, U. M.; Soragni, E. Tetrahedron 1997, 53, 17761.

(57) (a) Gilbert, B. C.; Kalz, W.; Lindsay, C. I.; McGrail, P. T.; Parsons, A. F.; Whittaker, D. T. E. Tetrahedron Lett. 1999, 40, 6095. (b) Huther, N.; McGrail, P. T.; Parsons, A. F. Eur. J. Org. Chem. 2004, 1740.

(58) Beck, A. L.; Mascal, M.; Moody, C. J.; Slawin, A. M. Z.; Williams, D. J.; Coates, W. J. J. Chem. Soc., Perkin Trans. 1 1992, 797.

(59) For a review on the Witkop cyclization, see: Gritsch, P. J.; Leitner, C.; Pfaffenbach, M.; Gaich, T. Angew. Chem. Int. Ed. 2014, 53, 1208.

(60) Boivin, J.; Yousfi, M.; Zard, S. Z. Tetrahedron Lett. 1994, 35, 5629.

(61) (a) Quiclet-Sire, B.; Saunier, J.-B.; Zard, S. Z. Tetrahedron Lett. 1996, 37, 1397. (b) Cassayre, J.; Quiclet-Sire, B.; Saunier, J.-B.; Zard, S. Z. Tetrahedron 1998, 54, 1029.

(62) Cassayre, J.; Dauge, D.; Zard, S. Z. Synlett 2000, 471.

(63) Boivin, J.; Yousfi, M.; Zard, S. Z. Tetrahedron Lett. 1994, 35, 9553.

(64) Boivin, J.; Yousfi, M.; Zard, S. Z. Tetrahedron Lett. 1997, 38, 5985.

(65) Cassayre, J.; Quiclet-Sire, B.; Saunier, J.-B.; Zard, S. Z. Tetrahedron Lett. 1998, 39, 8995.

(66) Cassayre, J.; Zard, S. Z. Synlett 1999, 501.

(67) Cassayre, J.; Zard, S. Z. J. Organomet. Chem. 2001, 624, 316.

(68) For a review on HAT, see: Nechab, M.; Mondal, S.; Bertrand, M. P. Chem. Eur. J. 2014, 20, 16034.

(69) Justicia, J.; Álvarez de Cienfuegos, L.; Campaña, A. G.; Miguel, D.; Jakoby, V.; Gansäuer, A.; Cuerva, J. M. Chem. Soc. Rev. 2011, 40, 3525.

(70) Diaba, F.; Gómez-Bengoa, E.; Cuerva, J. M.; Bonjoch, J.; Justicia, J. RSC Adv. 2016, 6, 55360.

(71) For mechanistic studies of the hydrogen atom transfer process from THF, see: (a) Jin, J.; Newcomb, M. J. Org. Chem. 2008, 73, 7901. (b) Paradas, M.; Campaña, A. G.; Jiménez, T.; Robles, R.; Oltra, J. E.; Buñuel, E.; Justicia, J.; Cárdenas, D. J.; Cuerva, J. M. J. Am. Chem. Soc. 2010, 132, 12748.

(72) Doi, N.; Takeda, N.; Miyata, O.; Ueda, M. J. Org. Chem. 2016, 81, 7855.

(73) Naito, T.; Saito, A.; Ueda, M.; Miyata, O. Heterocycles 2005, 65, 1857.

(74) Ishibashi, H.; Haruki, S.; Uchiyama, M.; Tamura, O.; Matsuo, J.-I. Tetrahedron Lett. 2006, 47, 6263.

(75) Ishibashi, H.; Sasaki, M.; Taniguchi, T. Tetrahedron 2008, 64, 7771.

(76) Taniguchi, T.; Kawajiri, R.; Ishibashi, H. ARKIVOC 2008, (xiv), 7.

(77) Taniguchi, T.; Sasaki, M.; Ishibashi, H. Heterocycles 2010, 80, 657.

(78) (a) Parsons, A. F.; Taylor, R. J. K. J. Chem. Soc., Chem. Commun. 1993, 1224. (b) Parsons, A. F.; Taylor, R. J. K. J. Chem. Soc., Perkin Trans. 1 1994, 1945. (c) Bryans, J. S.; Large, J. M.; Parsons, A. F. Tetrahedron Lett. 1999, 40, 3487.
(79) (a) Goodall, K.; Parsons, A. F. Tetrahedron 1996, 52, 6739. (b) Bryans, J. S.; Large, J. M.; Parsons, A. F. J. Chem. Soc., Perkin Trans. 1 1999, 2897.

(80) (a) Ishibashi, H.; Higuchi, M.; Ohba, M.; Ikeda, M. Tetrahedron Lett. 1998, 39, 75. (b) Ishibashi, H.; Kodama, K.; Higuchi, M.; Muraoka, O.; Tanabe, G.; Takeda, Y. Tetrahedron 2001, 57, 7629. (c) Ikeda, M.; Ohtani, S.; Yamamoto, T.; Sato, T.; Ishibashi, H. J. Chem. Soc., Perkin Trans. 1 1998, 1763.

(81) Quirante, J.; Escolano, C.; Diaba, F.; Bonjoch, J. J. Chem. Soc., Perkin Trans. 1 1999, 1157.

(82) (a) Quirante, J.; Diaba, F.; Vila, X.; Bonjoch, J.; Lago, E.; Molins, E. C. R. Acad. Sci. Paris 2001, 4, 513. (b) Marin, M. L.; Zaragoza, R. J.; Miranda, M. A.; Diaba, F.; Bonjoch, J. Org. Biomol. Chem. 2011, 9, 3180.

(83) For memory of chirality (MOC) in radical cyclizations, inter alia, see: (a)Curran, D. P.; Liu, W. D.; Chen, C. H. T. J. Am. Chem. Soc. 1999, 121, 11012. (b) Dalgard, J. E.; Rychnovsky, S. D. Org. Lett. 2004, 6, 2713. (c) Zhao, H.; Hsu, D. C.; Carlier, P. R. Synthesis 2005, 1. (d) Gloor, C. S.; Dénès, F.; Renaud, P. Free Radical Res 2016, in press; DOI: 10.1080/10715762.2016.1232485.

(84) Diaba, F.; Montiel, J. A.; Bonjoch, J. Tetrahedron 2013, 69, 4883.

(85) Vila, X.; Quirante, J.; Paloma, L.; Bonjoch, J. Tetrahedron Lett. 2004, 45, 4661.

(86) Quirante, J.; Vila, X.; Paloma, L.; Guiu, J. M.; Bonjoch, J. Tetrahedron 2007, 63, 1372.

(87) Quirante, J.; Escolano, C.; Diaba, F.; Bonjoch, J. Heterocycles 1999, 50, 731 .

(88) Quirante, J.; Escolano, C.; Costejà, L.; Bonjoch, J. Tetrahedron Lett. 1997, 38, 6901.

(89) Quirante, J.; Escolano, C.; Massot, M.; Bonjoch, J. Tetrahedron 1997, 53, 1391.

(90) (a) Quirante, J.; Escolano, C.; Bosch, J.; Bonjoch, J. J. Chem. Soc., Chem. Commun. 1995, 2141. (b) Quirante, J.; Escolano, C.; Merino, A.; Bonjoch, J. J. Org. Chem. 1998, 63, 968.

(91) Quirante, J.; Torra, M.; Diaba, F.; Escolano, C.; Bonjoch, J. Tetrahedron: Asymmetry 1999, 10, 2399.

(92) Diaba, F.; Montiel, J. A.; Bonjoch, J. Chem. Commun 2016, 52, 14031.

(93) Barltrop, J. A.; Bradbury, D. J. Am. Chem. Soc. 1973, 95, 5085.

(94) (a) For a review on borohydrides in radical chemistry, see: Kawamoto, T.; Ryu, I. Org. Biomol. Chem. 2014, 12, 9733. (b) For mechanistic studies, see: Kawamoto, T.; Uehara, S.; Hirao, H.; Fukuyama, T.; Matsubara, H.; Ryu, I. J. Org. Chem. 2014, 79, 3999.

(95) Coussanes, G. Ph.D. Dissertation; University of Barcelona: Spain, 2016.

(96) (a) Watanabe, Y.; Ueno, Y.; Tanaka, C.; Okawara, M.; Endo, T. Tetrahedron Lett. 1987, 28, 3953. (b) Ram, R. N.; Gupta, D. K. Adv. Synth. Catal. 2016, 358, 3254.

(97) (a) Lee, G. M.; Weinreb, S. M. J. Org. Chem. 1990, 55, 1281. (b) Brill, Z. C.; Grover, H. K.; Maimone, T. J. Science 2016, 352, 1078.

(98) (a) Nagashima, H.; Wakamatsu, H.; Itoh, K.; Tomo, Y.; Tsuji, J. Tetrahedron Lett. 1983, 24, 2395. (b) Takano, S.; Nishizawa, S.; Akiyama, M.; Ogasawara, K. Heterocycles 1984, 22, 1779. (c) Helliwell, M.; Fengas, D.; Knight, C. K.; Parker, J.; Quayle, P.; Raftery, J.; Richards, S. N. Tetrahedron Lett. 2005, 46, 7129. 